\title{
Oxidation State +IV in Group 12 Chemistry. Ab Initio Study of Zinc(IV), Cadmium(IV), and Mercury(IV) Fluorides
}

\author{
Martin Kaupp, ,† Michael Dolg, ${ }^{\dagger}$ Hermann Stoll, ${ }^{\ddagger}$ and Hans Georg von Schnering ${ }^{\dagger}$ \\ Max-Planck-Institut für Festkörperforschung, Heisenbergstrasse 1, D-70565 Stuttgart, FRG, and Institut \\ für Theoretische Chemie, Universität Stuttgart, Pfaffenwaldring 55, D-70569 Stuttgart, FRG
}

Received July $8,1993^{\circ}$

\begin{abstract}
Mercury(IV) fluoride, $\mathrm{HgF}_{4}$, is thermodynamically stable or only slightly endothermic with respect to gaseous $\mathrm{HgF}_{2}$ $+\mathrm{F}_{2}$ and might be accessible via fluorination of $\mathrm{HgF}_{2}$, e.g. by $\mathrm{KrF}_{2}$. This is the result of high-level quasirelativistic pseudopotential QCISD(T) calculations. In contrast, the existence of $\mathrm{CdF}_{4}$ is unlikely and that of $\mathrm{ZnF}_{4}$ even more so. The easier oxidation of $\mathrm{HgF}_{2}$, compared to $\mathrm{CdF}_{2}$ or $\mathrm{ZnF}_{2}$, is due to a relativistic destabilization of the $\mathrm{Hg}$ IL $\mathrm{F}$ bonds rather than to a relativistic stabilization of $\mathrm{HgF}_{4}$. Spin-orbit coupling also contributes to a stabilization of $\mathrm{HgF}_{4}$ vs $\mathrm{HgF}_{2}+\mathrm{F}_{2}$, but only slightly. The performance of various computational levels to treat electron correlation and of a general basis-set contraction scheme based on atomic natural orbitals have been evaluated. The characterization of molecular $\mathrm{HgF}_{4}$ should be possible via vibrational spectroscopy, as the calculated harmonic frequencies differ considerably from those of other possible species that might be present in the reaction mixture. Calculations on anionic model complexes and on the dimers $\left(\mathrm{HgF}_{4}\right)_{2}$ and $\left(\mathrm{HgF}_{2}\right)_{2}$ show that $\mathrm{HgF}_{4}$ gains only limited additional stability by anionic complexation or by aggregation. Thus, any successful synthesis should involve conditions where the lattice energy of $\mathrm{HgF}_{2}$ is not relevant (e.g. gas-phase molecular beam experiments or reactions in solution).
\end{abstract}

\section{Introduction}

The highest known formal oxidation state of the group 12 elements $\mathrm{Zn}, \mathrm{Cd}$, and $\mathrm{Hg}$ is II. ${ }^{1-3}$ Only one single report of a short-lived electrochemically generated $\mathrm{Hg}$ (III) species in solution exists. ${ }^{4}$ Oxidation of group 12 elements beyond the +II state involves ionization and participation in bonding of the metal ( $n$ $-1)$ d electrons. This would transform these post-transition metals into transition elements and thus extend the range of the transition metal rows within the periodic table.

Partly due to the relativistic contraction and stabilization of the $6 \mathrm{~s}$-orbital and to the relativistic expansion and destabilization of the 5d-orbitals, ${ }^{5}$ such an oxidation beyond the +II state is most likely for the heavy element mercury. Table 1 shows the ionization energies (IE) of the group 12 elements. Obviously, the first two IE of mercury are higher, and the third and fourth IE are lower than the corresponding values for $\mathrm{Zn}$ or $\mathrm{Cd}$. Inclusion of relativistic effects is essential to reproduce the experimental values for the heavy element mercury. Comparison of the two bottom rows shows the considerable increase of the first and second IE, and the decrease of the third and fourth IE for mercury due to relativity. It is well-known that the +III state is much more important in gold chemistry than for the lighter group 11 elements, $\mathrm{Ag}$ and $\mathrm{Cu},{ }^{1-3}$ and the largely relativistic origin of this preference for higher oxidation states has been verified. ${ }^{6}$ In general, the third-row transition elements tend to exhibit higher oxidation

- Author to whom correspondence should be addressed. Temporary address from Nov 1993 through Oct 1994: Departement de Chimie, Université de Montréal, C.P. 6128, Succ. A, Montréal, Québec H3C 3J7, Canada.

Max-Planck-Institut für Festkörperforschung.

Universitåt Stuttgart.

- Abstract published in Advance ACS Abstracts, April 1, 1994.

(1) Comprehensive Coordination Chemistry; Wilkinson, G., Ed.; Pergamon Press: Oxford, England, 1987; Vol. 5.

(2) Aylett, B. J. In Comprehensive Inorganic Chemistry; Trotman-Dickenson, A. F., Ed.; Pergamon Press: Oxford, England, 1973, Vol. 3.

(3) (a) Cotton, F. A.; Wilkinson, G. Advanced Inorganic Chemistry, 5th ed.; Wiley: Ed. New York, 1988. (b) Greenwood, N. N.; Earnshaw, A. Chemistry of the Elements; Pergamon Press: Oxford, England, 1984.

(4) Deming, R. L.; Allred, A. L.; Dahl, A. R.; Herlinger, A. W.; Kestner, M. O. J. Am. Chem. Soc. 1976, 98, 4132 .

(5) For reviews of relativistic effects on chemical properties, see, e.g.; (a) Pyykko, P. Chem. Rev. 1988, 88, 563. (b) Pyykkô, P.; Desclaux, J. P Acc. Chem. Res. 1979, 12, 276. (c) Pitzer, K. S. Acc. Chem. Res. 1979, 12, 271. (d) Schwarz, W. H. E. in Theoretical Models of Chemical Bonding, Maksic, B., Ed.; Springer: Berlin, 1990; Vol. 2, p 593.
Table 1. Calculated and Experimental First through Fourth Ionization Energies of the Group 12 Elements (eV)

\begin{tabular}{llllll}
\hline & & \multicolumn{1}{c}{ I } & \multicolumn{1}{c}{ II } & III & IV \\
\hline $\mathrm{Zn}$ & exptl $^{a}$ & 9.391 & 17.96 & 39.7 & 59.4 \\
& calcd $^{b}$ & 9.14 & 17.71 & 39.64 & 59.31 \\
$\mathrm{Cd}$ & expt1 $^{a}$ & 8.991 & 16.904 & 37.47 & \\
& calcd $^{b}$ & 8.74 & 16.66 & 37.42 & 52.22 \\
$\mathrm{Hg}$ & exptl $^{a}$ & 10.43 & 18.751 & 34.2 & \\
& calcd(rel) $^{b, c}$ & 10.20 & 18.48 & $34.17 e$ & $49.16^{e}$ \\
& calcd(nr) $^{b, d}$ & 8.23 & 15.48 & 36.01 & 50.13
\end{tabular}

a Cf. C. E. Moore, Ionization Potentials and Ionization Limits Derived from the Analysis of Optical Spectra; National Standard Reference Data Series 34; NBS: Washington, DC, 1970. ${ }^{b}$ Averaged coupled pair functional results with ANO-basis (cf. computational methods section). 'Quasirelativistic ECP. 'Nonrelativistic ECP. These values include corrections for spin-orbit coupling in $\mathrm{Hg}^{3+}\left({ }^{2} \mathrm{D}_{5 / 2}\right)(0.77 \mathrm{eV})$ and in $\mathrm{Hg}^{4+}\left({ }^{3} \mathrm{~F}_{4}\right)(0.45 \mathrm{eV})$ obtained in numerical all-electron Dirac-Fock calculations using the program Grasp (Dyall, K. G.; Grant, I. P.; Johnson, C. T.; Parpia, F. A.; Plummer, E. P. Comput. Phys. Commun. 1989, 55, 425).

states (or to be more stable in higher oxidation states) than the lighter metals of a given triad.1-3 Figure 1 shows the trends of the highest known oxidation numbers for the elements of the three transition-metal rows. After a regular increase following the maximum group valency up to $\mathrm{Mn}$ (VII), Ru(VIII), and Os(VIII), there is a less regular decrease throughout the last third of a given row. The discovery of $\mathrm{Cu}(\mathrm{IV})$ in $\mathrm{Cs}_{2} \mathrm{CuF}_{6}{ }^{7}$ and of $\mathrm{Au}(\mathrm{V})$ in $\mathrm{CsAuF}_{5}{ }^{8}$ in the early 1970 s has spurred interest in group 12 elements exhibiting valencies above two. However, the above-mentioned report of a short-lived $\mathrm{Hg}$ (III) species ${ }^{4}$ remains singular.

In analogy to gold(III), we have considered the existence of mercury(IV) by ab initio calculations. In a preliminary communication, 9 we have reported computational evidence that

(6) (a) Schwerdtfeger, P.; Boyd, P. D. W.; Brienne, S.; Burrell, A. K. Inorg. Chem. 1991, 31, 3481. (b) Schwerdtfeger, P. J. Am. Chem. Soc. 1989, 111,7261 . (c) Schwerdtfeger, P.; Dolg, M.; Schwarz, W. H. E.; Bowmaker, G. A.; Boyd, P. D. W. J. Chem. Phys. 1989, 91, 1762. Also see ref $5 b$.

(7) Harnischmacher, W.; Hoppe, R. Angew. Chem. 1973, 85, 590; Angew. Chem.; Int. Ed. Engl. 1973, 12, 582.

(8) Leary, K.; Bartlett, N. J. Chem. Soc., Chem. Commun. 1972, 1, 903.

(9) Kaupp, M.; v. Schnering, H. G. Angew. Chem. 1993, 105, 952; Angew. Chem. Int. Ed. Engl. 1993, 32, 861 . 


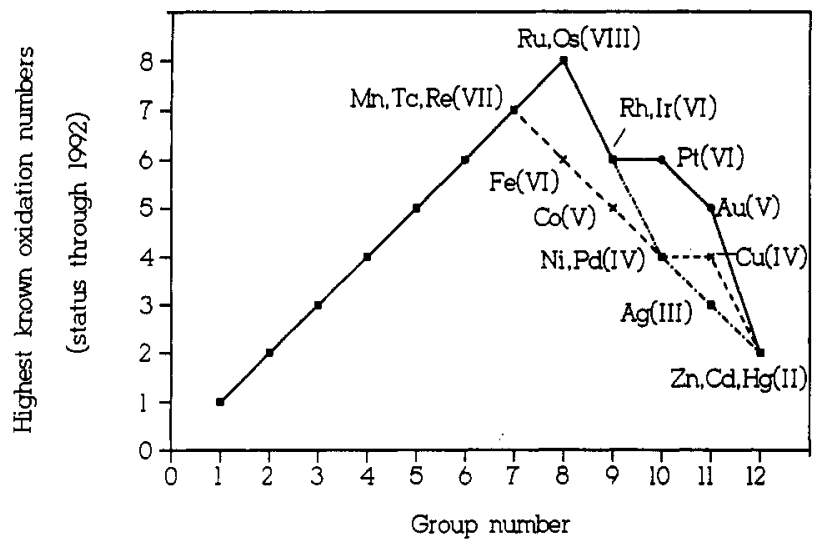

Figure 1. Highest known oxidation numbers for the elements of the first, second, and third transition metal row, respectively.

suggests mercury(IV) fluoride, $\mathrm{HgF}_{4}$, to have a good chance for existing as a free molecule in the gas phase. A possible preparation route via fluorination of $\mathrm{HgF}_{2}$ by $\mathrm{KrF}_{2}$ has been suggested. ${ }^{9} \mathrm{We}$ now provide a detailed ab initio comparison of the molecular and electronic structures and of the stabilities of $\mathrm{HgF}_{4}$ and its lighter congeners, $\mathrm{ZnF}_{4}$ and $\mathrm{CdF}_{4}$. Different methods to treat electron correlation in these species are evaluated. The influence of relativistic effects on bond distance, stability, and electronic structure of $\mathrm{HgF}_{4}$ will be discussed. The possible stabilization of $\mathrm{HgF}_{4}$ by anionic complexation or by aggregation will also be considered.

The setup of this paper is as follows: section II describes the computational methods employed. In section III, we critically compare various theoretical approaches, and establish the accuracy of our calculations. Readers more interested in the general chemical discussion may wish to skip sections II and III. In section IV, the influence of relativistic effects on bond distances and stabilities of $\mathrm{HgF}_{4}$ and $\mathrm{HgF}_{2}$ is discussed. In section $\mathrm{V}$, we compare the stability of the tetra- and difluorides of $\mathrm{Zn}, \mathrm{Cd}$, and $\mathrm{Hg}$, and discuss possible preparation routes for $\mathrm{HgF}_{4}$. We detail the electronic structures of the di- and tetrafluorides in section VI. The calculated harmonic vibrational frequencies for $\mathrm{HgF}_{4}$, $\mathrm{HgF}_{2}$ and $\left(\mathrm{HgF}_{2}\right)_{2}$ are evaluated in section VII. In section VIII, the possible stabilization of $\mathrm{HgF}_{4}$ by anionic complexation or by aggregation is discussed. Finally, section IX summarizes our major conclusions.

\section{Computational Methods}

We have used quasirelativistic 20-valence-electron pseudopotentials for $\mathrm{Zn},{ }^{10} \mathrm{Cd},{ }^{11}$ and $\mathrm{Hg} .{ }^{11}$ Comparative calculations with a nonrelativistic $\mathrm{Hg}$ pseudopotential ${ }^{11}$ provide information on the influence of relativistic effects on molecular properties of the mercury compounds. For $\mathrm{Kr}$ and F, we employed quasirelativistic 8- and 7-valence-electron pseudopotentials, respectively. 12,13

Two different basis-set contraction schemes have been employed: Segmented (8s7p6d)/[6s5p3d] GTO valence basis sets published with the $\mathrm{Zn}, \mathrm{Cd}$, and $\mathrm{Hg}$ pseudopotentials ${ }^{10,11}$ have been used with corresponding segmented valence basis sets for $\operatorname{Kr}((6 \mathrm{~s} 6 \mathrm{p} 1 \mathrm{~d}) /[4 \mathrm{~s} 4 \mathrm{pld}])^{12}$ and $F((5 s 5 p l d) /[3 s 3 p 1 d]){ }^{14}$ This basis set combination will be designated basis- $A$. The addition of one metal f-function (cf. Table 2) leads to basis-B. In some cases, a set of two f-functions (Table 2) and a larger $(7 \mathrm{~s} 7 \mathrm{p} 3 \mathrm{~d} 1 \mathrm{f}) /[5 \mathrm{~s} 5 \mathrm{p} 3 \mathrm{~d} 1 \mathrm{f}]$ fluorine basis ${ }^{15}$ have been used (basis-

(10) Dolg, M.; Wedig, U.; Stoll, H.; Preuss, H. J. Chem. Phys. 1987, 86, 866.

(11) Andrae, D.; Håussermann, U.; Dolg, M.; Stoll, H.; Preuss, H. Theor. Chim. Acta 1990, 77, 123 .

(12) Nicklass, A., Dolg, M.; Stoll, H.; Preuss, H. Unpublished results.

(13) Bergner, A.; Dolg, M.; Küchle, W.; Stoll, H.; Preuss, H. Mol. Phys. $1993,80,1431$.

(14) (a) Kaupp, M.; Schleyer, P. v. R.; Stoll, H.; Preuss, H. J. Am. Chem. Soc. 1991, 113, 6012. (b) Gaussian Basis Sets for Molecular Calculations, Huzinaga, S., Ed., Elsevier: New York, 1984.

(15) (a) Dolg, M. Dissertation, Universităt Stuttgart, 1989. (b) Frisch, $M$ J.; Pople, J. A.; Binkley, J. S. J. Chem. Phys. 1984, 80, 3265 (d-and f-exponents, one diffuse sp-set with $\alpha=0.09$ has also been added).
Table 2. f-Function Exponents Used for $\mathrm{Zn}, \mathrm{Cd}$, and $\mathrm{Hg}^{a}$

\begin{tabular}{lcc}
\hline & single f-function & two f-functions \\
\hline $\mathrm{Zn}$ & 3.90 & $6.15,1.65$ \\
$\mathrm{Cd}$ & 1.80 & $2.80,0.80$ \\
$\mathrm{Hg}$ & 0.486 & $0.95,0.12$
\end{tabular}

a Optimized in atomic QCISD calculations using the quasirelativistic pseudopotentials and segmented $6 \mathrm{~s} 5 \mathrm{p} 3 \mathrm{~d}$ valence bases.

C). To obtain even larger fractions of the electron-correlation energy contributions in post-SCF calculations while keeping the computational effort manageable, we have used a general contraction scheme. Thus, the same primitive metal $8 \mathrm{~s} 7 \mathrm{p} 6 \mathrm{~d} 2 \mathrm{f}$ valence basis sets ${ }^{10,11}$ corresponding to basis $\mathrm{C}$ have been contracted to $4 \mathrm{~s} 3 \mathrm{p} 3 \mathrm{~d} 2 \mathrm{f}$ using atomic natural orbital (ANO) ${ }^{16}$ coefficients obtained in atomic averaged coupled pair functional (ACPF) ${ }^{17}$ calculations. Similarly, the $\mathrm{Kr} 6 \mathrm{~s} 6 \mathrm{p}$ valence basis ${ }^{12}$ was augmented by a $5 \mathrm{~d} 3 \mathrm{f} \operatorname{set}^{18}$ and contracted to $2 \mathrm{~s} 2 \mathrm{p} 3 \mathrm{~d} 2 \mathrm{f}$. The fluorine $7 \mathrm{~s} 7 \mathrm{p} 3 \mathrm{~d}$ If primitive valence basis set was contracted to a $3 \mathrm{~s} 3 \mathrm{p} 3 \mathrm{~d}$ lf $\mathrm{ANO}$ basis. The ANO contraction coefficients obtained for $\mathrm{Zn}, \mathrm{Cd}, \mathrm{Hg}$, and F are given in Tables 19-22 in the Appendix. Table 23 in the Appendix shows the atomic ACPF contraction eirrors with both segmented and general contractions. The performance of segmented vs. general contraction schemes will be discussed in section III.

Electron correlation has been included at the second-order MøllerPlesset perturbation theory level (MP2), ${ }^{19}$ at the singles + doubles quadratic configuration interaction level (QCISD), ${ }^{20}$ and for the most accurate calculations at the $\mathrm{QCISD}(\mathrm{T})$ level with perturbation-theoretical inclusion of connected triple substitutions. ${ }^{20}$ The ionization energies for $\mathrm{Zn}, \mathrm{Cd}$, and $\mathrm{Hg}$ given in Table 1 have been calculated at the ACPF level, ${ }^{17}$ using the ANO metal basis sets. The calculations employed the Gaussian $90,{ }^{21}$ Gaussian $92,{ }^{22}$ and MOLPRO ${ }^{23}$ program systems, except for calculations including spin-orbit coupling, which are described in section IV.

In the following we will use the conventional designations for the computational levels, ${ }^{24}$ e.g. a QCISD calculation using basis-B at the structure optimized at the MP2 level using basis-A will be abbreviated by QCISD/basis-B//MP2/basis-A. Full Hartree-Fock (HF) and MP2 geometry optimizations using basis- $A$ have been carried out for $\mathrm{MF}_{4}(\mathrm{M}$ $=\mathrm{Zn}, \mathrm{Cd}, \mathrm{Hg}$; in $D_{4 h}$ symmetry), $\mathrm{MF}_{2}\left(D_{\infty h}\right), \mathrm{HgF}_{5}$ (in $C_{40}$ and $D_{3 h}$ ), $\mathrm{HgF}_{3}-\left(D_{3 h}\right), \mathrm{HgF}_{6}{ }^{2-}\left(D_{4 h}\right), \mathrm{HgF}_{4}{ }^{2-}\left(T_{d}\right),\left(\mathrm{HgF}_{2}\right)_{2}\left(C_{2 h}\right)$, and $\left(\mathrm{HgF}_{4}\right)_{2}$ $\left(C_{2 h}\right)$, as well as $\mathrm{KrF}_{2}\left(D_{\infty h}\right)$. HF/basis-A harmonic frequency analyses have been performed for all $\mathrm{MF}_{4}$ and for all mercury species considered (except for $\left.\left(\mathrm{HgF}_{4}\right)_{2}\right)$. The $D_{3 h}$ form of $\mathrm{HgF}_{5}$ - has been found to be a transition state; all other structures are minima at this theoretical level. The $\mathrm{M}-\mathrm{F}$ distances in $\mathrm{MF}_{4}$ and in $\mathrm{MF}_{2}$ have additionally been computed using the MP2/basis-B, the ANO-MP2, and the ANO-QCISD methods.

(16) Almlöf, J.; Taylor, P. R. J. Chem. Phys. 1987, 86, 4070.

(17) Gdaniz, R. J.; Ahlrichs, R. Chem. Phys. Lett. 1988, 143, 413.

(18) The two larger d-exponents of Nicklass' $3 d$ lf polarization set (cf. ref 12), and the three larger d-exponents plus the three f-exponents from the $5 \mathrm{~d} 3 \mathrm{f}$ set of Maroulis and Thakkar (Maroulis, G.; Thakkar, A. J. J. Chem. Phys. 1988, 92, 4329) were combined to a $5 \mathrm{~d} 3 \mathrm{f}$ polarization set for $\mathrm{Kr}$.

(19) Møller, C.; Plesset, M. S. Phys. Rev. 1934, 46, 618.

(20) See, e.g.; Pople, J. A.; Head-Gordon, M.; Raghavachari, K. J. Chem. Phys. 1987, 87, 5968. Paldus, J.; Cizek, J.; Jeziorski, B. J. Chem. Phys. 1989, 90, 4356. 1990, 93, 1485. Raghavachari, K.; Head-Gordon, M.; Pople, J. A. J. Chem. Phys. 1990, 93, 1486.

(21) Frisch, M. J.; Head-Gordon, M.; Trucks, G. W.; Foresman, J. B.; Schlegel, H. B.; Raghavachari, K.; Robb, M.; Binkely, J.S.; Gonzalez, C.; DeFrees, D. J.; Fox, D. J.; Whiteside, R. A.; Seeger, R.; Melius, C. F.; Baker, J.; Kahn, L. R.; Stewart, J. J. P.; Topiol, S.; Pople, J. A. Gaussian 90, Revision F. Gaussian, Inc., Pittsburgh, PA, 1990.

(22) Frisch, M. J.; Trucks, G. W.; Head-Gordon, M.; Gill, P. M. W.; Wong, M. W.; Foresman, J. B.; Johnson, B. G.; Schlegel, H. B.; Robb, M. A.; Replogle, E.S.; Gomperts, R.; Andres, J. L.; Raghavachari, K.; Binkley, J. S.; Gonzalez, C.; Martin, R. L.; Fox, D. I.; DeFrees, D. J.; Baker, J.; Stewart, J. P.; Pople, J. A., Gaussian 92, Revision A. Gaussian, Inc., Pittsburgh, PA, 1992.

(23) Program system MOLPRO written by Werner, H. J.; Knowles, P. J., with contributions by Almlof, J.; Amos, R.; Elbert, S.; Hampel, C.; Meyer, W.; Peterson, K.; Pitzer, R.; Stone, A.; see, e.g.: (a) Werner, H. J. Adv. Chem. Phys. 1987, 69, 1. (b) Werner, H. J.; Knowles, P. J. J. Chem. Phys. 1988, 89, 5803. (c) Knowles, P. J.; Werner, H. J. Chem. Phys. Lett. 1988, 145, 514 (cf. Hampel, C.; Peterson, K.; Werner, H.-J. Chem. Phys. Lett. 1992, 190, 1, and references cited therein, for the QCI program).

(24) Explanations of standard levels of theory may be found in: Hehre, W. J.; Radom, L.; Schleyer, P. v. R.; Pople, J. A. Ab Initio Molecular Orbital Theory; Wiley: New York, 1986. 
Table 3. Comparison of $\mathrm{M}-\mathrm{F}$ Distances $(\AA)$ in $\mathrm{MF}_{4}(\mathrm{M}=\mathrm{Zn}, \mathrm{Cd}$, $\mathrm{Hg}$ ) Calculated at Various Computational Levels (in $D_{4 h}$ Symmetry)

\begin{tabular}{lccccc}
\hline M & $\begin{array}{c}\text { HF/ } \\
\text { basis-A }\end{array}$ & $\begin{array}{c}\text { MP2/ } \\
\text { basis A }\end{array}$ & $\begin{array}{c}\text { MP2/ } \\
\text { basis-B }\end{array}$ & $\begin{array}{c}\text { ANO- } \\
\text { MP2 }\end{array}$ & $\begin{array}{c}\text { ANO- } \\
\text { QCISD }\end{array}$ \\
\hline $\mathrm{Zn}$ & 1.721 & 1.827 & 1.802 & 1.797 & 1.736 \\
$\mathrm{Cd}$ & 1.871 & 2.010 & 1.981 & 1.930 & 1.872 \\
$\mathrm{Hg} \mathrm{nF}$ & 1.953 & 2.153 & 2.050 & 2.032 & 1.960 \\
rel $^{b}$ & 1.886 & 1.962 & 1.923 & 1.904 & 1.884
\end{tabular}

a Nonrelativistic mercury pseudopotential. ${ }^{b}$ Quasirelativistic mercury pseudopotential.

Table 4. Comparison of $\mathrm{M}-\mathrm{F}$ Distances $(\AA)$ in $\mathrm{MF}_{2}(\mathrm{M}=\mathrm{Zn}, \mathrm{Cd}$, $\mathrm{Hg}$ ) Calculated at Various Computational Levels (in $D_{\infty \mathrm{h}}$ Symmetry)

\begin{tabular}{lccccc}
\hline M & $\begin{array}{c}\text { HF/ } \\
\text { basis-A }\end{array}$ & $\begin{array}{c}\text { MP2/ } \\
\text { basis-A }\end{array}$ & $\begin{array}{c}\text { MP2/ } \\
\text { basis-B }\end{array}$ & $\begin{array}{c}\text { ANO- } \\
\text { MP2 }\end{array}$ & $\begin{array}{c}\text { ANO- } \\
\text { QCISD }\end{array}$ \\
\hline $\mathrm{Zn}$ & 1.743 & 1.741 & 1.728 & 1.717 & 1.727 \\
$\mathrm{Cd}$ & 1.949 & 1.959 & 1.939 & 1.908 & 1.920 \\
$\mathrm{Hg} \mathrm{nr}$ & 2.067 & 2.079 & 2.037 & 2.026 & 2.036 \\
rel $^{b}$ & 1.953 & 1.965 & 1.924 & 1.909 & 1.924
\end{tabular}

a Nonrelativistic mercury pseudopotential. ${ }^{b}$ Quasirelativistic mercury pseudopotential.

Reaction energies have been studied at the MP2/basis-B//MP2/basisA, QCISD/basis-B//MP2/basis-A, and (for some cases) at the ANOMP2//ANO-MP2, ANO-QCISD//ANO-QCISD, and ANO-QCISD(T)//ANO-QCISD levels. All electrons outside the pseudopotential cores have been correlated in these MP2 and QCI calculations, except for $\mathrm{HgF}_{6}{ }^{2-}$ where, due to program limitations, the $5 \mathrm{~s}$ and $5 \mathrm{p}$ shells on mercury had to be frozen in the QCI calculations (for consistency in the reaction energies, corresponding single-point calculations also have been done for $\mathrm{HgF}_{4}{ }^{2-}$ and $\mathrm{HgF}_{5}-$ ). Calculations of open-shell fragments (e.g. the fluorine atom) are based on UHF reference wave functions.

\section{Evaluation of Different Computational Approaches}

Bond Distances. Tables 3 and 4 summarize the $M-F$ distances obtained at various theoretical levels for $\mathrm{MF}_{4}$ and $M F_{2}(M=Z n$, $\mathrm{Cd}, \mathrm{Hg}$ ), respectively. For the tetrafluorides, the $\mathrm{HF}$ and the ANO-QCISD results agree within $0.015 \AA$. The MP2/basis-A distances are considerably too large (by up to $0.1 \AA$ ), but the error is slightly reduced upon inclusion of a metal $f$-function (basis-B). In going from MP2/basis-A to MP2/basis-B to ANOMP2 (including two metal f-functions), the results approach the ANO-QCISD values. However, the remaining differences $r$ (ANO-MP2) - r(ANO-QCISD) are still ca. 0.06-0.07 $\AA$ except for the relativistic $\mathrm{Hg}$-ECP results, where the error is only 0.02 $\AA$. This indicates problems of the MP2 method in describing the bonding in these $d^{8}$ species, probably due to nonnegligible nondynamical correlation effects (cf. below). It is tempting to ascribe the bond lengthening from $\mathrm{HF} /$ basis-A to MP2/basis-A levels to the influence of "left-right correlation", 25 and the shortening upon inclusion of metal f-functions to angular or corevalence correlation (f-functions are important in describing angular correlation of the $(n-1)$ d shell). Interestingly, relativistic effects bring MP2 and QCISD in better agreement for $\mathrm{HgF}_{4}$. This may indicate reduced nondynamical correlation effects in the quasirelativistic calculations (cf. below).

The agreement between ANO-MP2 and ANO-QCISD distances for the $d^{10}$ difluorides is much better than for the $d^{8}$ tetrafluorides, the ANO-MP2 bond lengths being consistently somewhat (ca. 0.01-0.015 $\AA$ ) shorter. The HF distances are slightly (ca. $0.02-0.03 \AA$ ) larger than the ANO-QCISD values. The inclusion of $f$-functions in the metal basis set (basis-B, ANO) at the correlated level is necessary to reproduce the slight bond shortening compared to the HF values. These results indicate moderate contributions from angular correlation (slightly overestimated by the MP2 method) and considerably reduced leftright correlation compared to the more covalent tetrafluorides.

(25) See, e.g.: Kutzelnigg, W. Einführung in die Theoretische Chemie: Vol 2: Die Chemische Bindung, Verlag Chemie: Weinheim, Germany, 1978.
Table 5. QCISD Valence Energies with Uncontracted Basis Sets, ${ }^{a}$ Segmented Basis Sets, ${ }^{b}$ and Generally-Contracted ANO Basis-Sets ${ }^{c}$ and Contraction Errors

\begin{tabular}{lrrrrrr}
\hline & \multicolumn{3}{c}{ valence energies, au } & & errors, $10^{-3} \mathrm{au}$ \\
\cline { 2 - 4 } & uncontracted & \multicolumn{1}{c}{ segmd $^{b}$} & \multicolumn{1}{c}{ ANO $^{c}$} & & segmd & ANO \\
\hline $\mathrm{Hg}$ & -153.051415 & -152.956223 & -153.035946 & 95.2 & 15.5 \\
$\mathrm{~F}$ & -24.161738 & -24.154994 & -24.158058 & 6.7 & 3.7 \\
$\mathrm{~F}_{2}$ & -48.370913 & -48.357481 & -48.359738 & 13.3 & 11.2 \\
$\mathrm{HgF}_{2}$ & -201.560472 & -201.455353 & -201.527332 & 105.1 & 33.1 \\
$\mathrm{HgF}_{4}$ & & -249.805837 & -249.882323 & &
\end{tabular}

a 8s7p6d primitive valence basis set for $\mathrm{Hg}$ (quasirelativistic ecp); 7s7pdif for F. ${ }^{6}$ Segmented $6 s 5 \mathrm{p} 3 \mathrm{~d} 2 \mathrm{f}$ contraction for $\mathrm{Hg}$ and $4 \mathrm{~s} 4 \mathrm{p} 3 \mathrm{~d}$ lf for F. ' ANO 4s $3 p 3 d 2 f$ contraction for $\mathrm{Hg}$ and $3 s 3 p 3 d 1 f$ for $F$.

Table 6. Effect of Basis Set Contraction ${ }^{\sigma}$ on QCISD Reaction Energies $\left(\mathrm{kJ} \mathrm{mol}^{-1}\right)$

\begin{tabular}{cccc}
\multicolumn{1}{c}{ reaction } & uncontracted & segmd & ANO \\
\hline $\mathrm{F}_{2} \rightarrow 2 \mathrm{~F}$ & 124.5 & 125.0 & 114.5 \\
$\mathrm{HgF}_{2} \rightarrow \mathrm{Hg}+2 \mathrm{~F}$ & 487.2 & 496.6 & 460.2 \\
$\mathrm{HgF}_{4} \rightarrow \mathrm{Hg}+4 \mathrm{~F}$ & & 602.9 & 562.2 \\
$\mathrm{HgF}_{4} \rightarrow \mathrm{HgF}_{2}+\mathrm{F}_{2}$ & & -18.6 & -12.5
\end{tabular}

${ }^{a} \mathrm{Cf}$. Table $\mathrm{V}$ for basis sets and valence energies.

Basis-Set Contraction Effects on Energies. For an evaluation of the performance of the segmented and ANO general contraction schemes, Table 5 displays the QCISD valence energies for some atoms and molecules, as well as the contraction errors. Table 6 gives various QCISD reaction energies obtained without contraction, with segmented contractions, or with general contractions.

Generally, the absolute contraction errors for the ANO basis sets are smaller than those for the segmented basis sets (cf. Table 5 ), in spite of the smaller number of contracted groups. While there is not much experience with ANO contractions using pseudopotentials, ${ }^{26}$ these results indicate a good performance of the general contraction scheme.

However, as suggested by the atomization energies calculated for $\mathrm{F}_{2}, \mathrm{HgF}_{2}$, and $\mathrm{HgF}_{4}$ (Table 6), the atom-optimized ANO basis sets are somewhat biased toward the isolated atoms. Thus, the atomization energies obtained with the ANO basis sets for $\mathrm{F}_{2}$ and $\mathrm{HgF}_{2}$ are smaller (by ca. $10-15 \mathrm{~kJ} \mathrm{~mol}^{-1}$ per bond) than the uncontracted-basis results. The values calculated with the segmented basis deviate much less from the atomization energies obtained without basis set contraction, in spite of the smaller electron-correlation energy contributions recovered (note that the SCF contraction errors of the ANO basis sets are larger than those for the segmented contraction). Nevertheless, we will base most of our discussion beyond the MP2 level (QCI, ACPF) on results obtained with the ANO basis sets. The ANO contraction errors in the atomization energies are relatively small, and they tend to cancel, e.g. for the energy of the reaction $\mathrm{HgF}_{4} \rightarrow \mathrm{HgF}_{2}$ $+\mathrm{F}_{2}$ (cf. Table 6). Moreover, the smaller number of basis groups involved reduces the computational effort considerably, which is particularly important for the expensive QCISD(T) calculations. For example, a calculation for $\mathrm{HgF}_{4}$ using the segmented basis-C involves 218 contractions whereas the ANO calculations requires only 178 groups. The corresponding QCI calculation without contraction ( 268 primitive functions) would in any case be prohibitively expensive.

Performance of MP2, QCISD, and QCISD(T) for Atomization Energies. The atomization energies calculated for $\mathrm{MF}_{2}$ and $\mathrm{MF}_{4}$ $(\mathrm{M}=\mathrm{Zn}, \mathrm{Cd}, \mathrm{Hg}$ ) at the ANO-MP2, ANO-QCISD, and ANOQCISD(T) levels are shown in Table 7. Taking the best calculations, QCISD $(T)$, as a reference, we note a few general trends:

The performance of MP2 for the difluorides is acceptable, the values consistently being too large (compared to QCISD) by ca.

(26) Sousa, C.; Rubio, J.; Illas, F. J. Comput. Chem. 1992, 13, 148. 
Table 7. Calculated Atomization Energies $\left(\mathrm{kJ} \mathrm{mol}^{-1}\right)$ for $\mathrm{MF}_{4}$ and $\mathrm{MF}_{2}(\mathrm{M}=\mathrm{Zn}, \mathrm{Cd}, \mathrm{Hg})$

\begin{tabular}{lrccc}
\hline & ZPE $^{a}$ & ANO-MP2 $^{b}$ & ANO-QCISD $^{c}$ & ANO-QCISD(T) $^{c}$ \\
\hline $\mathrm{ZnF}_{2}$ & -10.2 & 816.7 & 736.9 & 749.1 \\
$\mathrm{CdF}_{2}$ & -8.6 & 677.7 & 621.3 & 636.3 \\
$\mathrm{HgF}_{2} \mathrm{nr}^{d}$ & -7.7 & 680.2 & 623.0 & 638.2 \\
$\mathrm{rel}^{c}$ & -9.2 & 510.6 & 460.2 & 481.2 \\
$\mathrm{ZnF}_{4}$ & -23.2 & 965.5 & 593.8 & 728.4 \\
$\mathrm{CdF}_{4}$ & -22.1 & 845.7 & 531.9 & 679.8 \\
$\mathrm{HgF}_{4} \mathrm{nr}^{d}$ & -21.0 & 861.0 & 589.5 & 695.5 \\
\multicolumn{1}{r}{ rele $^{e}$} & -23.4 & 735.3 & 562.2 & 642.7
\end{tabular}

a HF zero-point vibrational energy correction. $b / /$ ANO-MP2. $c / /$ ANO-QCISD. ${ }^{d}$ Nonrelativistic mercury pseudopotential. ' Quasirelativistic mercury pseudopotential.

6-9\%. The contributions of triple substitutions to the QCI results also are small, $2-4 \%$ of the QCISD(T) atomization energies.

For the atomization energies of the tetrafluorides, MP2 performs considerably worse, and the importance of triple excitations is significantly larger: The MP2 values are larger than the QCISD results by up to $33 \%$ (for $\mathrm{ZnF}_{4}$ ). Relativistic effects for $\mathrm{HgF}_{4}$ decrease the error from $24 \%$ to $14 \%$. The contributions from triple excitations range from ca. $13 \%\left(\mathrm{HgF}_{4}\right.$, relativistic $\mathrm{ECP})$ to $22 \%\left(\mathrm{CdF}_{4}\right)$. It is known that contributions from triple substitutions in a single-reference coupled-cluster treatment considerably improve the agreement with multireference $\mathrm{CI}$ results in cases with significant but moderate nondynamical correlation contributions, e.g. for $\mathrm{F}_{2}, \mathrm{O}_{3}$, etc. (also see below). ${ }^{27}$ This suggests a larger degree of nondynamical correlation for the tetrafluorides than for the difluorides, which is supported by the weights of the reference determinants in the QCISD calculations (ca. 0.85 for $\mathrm{MF}_{4}$ but ca. 0.90 for $\mathrm{MF}_{2}$ ). Hence, the treatment of electron correlation obviously is more demanding for the tetrafluorides than for the difluorides. We thus expect the ANO-QCISD(T) atomization energies for the latter to be more accurate. Unfortunately, no experimental results are available for the monomeric difluorides.

The failure of MP2 for the binding energies in many transition metal compounds is well documented. ${ }^{28}$ The present results allow the performance of MP2 to be compared for compounds of a given central atom $(\mathrm{Zn}, \mathrm{Cd}$, or $\mathrm{Hg})$ as a nontransition metal and as a transition metal. Thus, it can easily be verified that the failure of MP2 is intimately connected to the involvement of d-orbitals in bonding. As indicated by the improvement of the performance of $\mathrm{MP2}$ for $\mathrm{HgF}_{4}$ upon inclusion of the relativistic s-orbital contraction and d-orbital expansion, the problems of a perturbation-theory treatment for the tetrafluorides are also related to a "weak-interaction" situation, i.e. to poor overlap between metal d-orbitals and ligand orbitals. This is consistent with the discussion of electron correlation in closed-shell transition metal compounds given by Buijse and Baerends ${ }^{29}$ and with the frequent failure of low orders of the MPn series for systems with appreciably stretched bonds. ${ }^{30}$

Table 8 shows the calculated and experimental atomization energies for $\mathrm{KrF}_{2}$ and $\mathrm{F}_{2}$. Similar to the situation for the group 12 tetrafluorides discussed above, the contributions from triple excitations to the atomization energies are considerable for these two species ( $32 \%$ for $\mathrm{KrF}_{2}, 20 \%$ for $\mathrm{F}_{2}$ ), as noted previously for $\mathrm{F}_{2 .}{ }^{27} \mathrm{MP} 2$ overestimates the $\mathrm{QCI}$ atomization energies significantly in both cases. The reasonable agreement of the QCISD(T) results with experiment (to within ca. $40 \mathrm{~kJ} \mathrm{~mol}^{-1}$ for $\mathrm{KrF}_{2}$

(27) Scuseria, G. E.; Lee, T. J. J. Chem. Phys. 1990, 93, 5851.

(28) See, e.g.: Marsden, J. C.; Wolynec, P. P. Inorg. Chem, 1991, 30, 1681. Neuhaus, A.; Frenking, G.; Huber, C.; Gauss, J. Inorg. Chem. 1992, 31 , 5355. Jonas, V.; Frenking, G.; Gauss, J. Chem. Phys. Lett. 1992, 194 , 109.

(29) Buijse, M. A.; Baerends, E. J. J. Chem. Phys. 1990, 93, 4129.

(30) See, e.g.: Nobes, R. H.; Moncrieff, D.; Wong, M. W.; Radom, L.; Gill, P. M. W.; Pople, J. A. Chem. Phys. Lett. 1991, 182, 216, and references cited therein.
Table 8. Calculated and Experimental Atomization Energies (kJ $\mathrm{mol}^{-1}$ ) for $\mathrm{KrF}_{2}$ and $\mathrm{F}_{2}$

\begin{tabular}{lrrrrr}
\hline & ZPE & $\begin{array}{c}\text { ANO- } \\
\text { MP2 }^{b}\end{array}$ & $\begin{array}{c}\text { ANO- } \\
\text { QCISD }^{c}\end{array}$ & $\begin{array}{c}\text { ANO- } \\
\text { QCISD(T) }^{c}\end{array}$ & exptl \\
\hline $\mathrm{KrF}_{2}$ & -10.9 & +119.4 & +21.3 & +67.4 & $+99.5^{d}$ \\
$\mathrm{~F}_{2}$ & -7.1 & +166.6 & +114.5 & +142.9 & $+154.2^{e}$
\end{tabular}

${ }^{a}$ HF zero-point-vibrational energy correction. ${ }^{b} / /$ ANO-MP2. $c / /$ ANO-QCISD. ' Gunn, S. R. J. Phys. Chem. 1967, 71, 2934. 'Chase, M. W.; Davies, C. A.; Downey, J. R., Jr.; Frunip, D. J.; McDonald, R. A.; Syverd, A. N. JANAF Thermochemical Tables. J. Phys. Chem. Ref. Data 1985, 14, Suppl. No. 1.

Table 9. Calculated Reaction Energies $\left(\mathrm{kJ}\right.$ mol-1) for $\mathrm{MF}_{4} \rightarrow \mathrm{MF}_{2}$ $+\mathrm{F}_{2}(\mathrm{M}=\mathrm{Zn}, \mathrm{Cd}, \mathrm{Hg})$

\begin{tabular}{lcccc}
\hline \multicolumn{1}{c}{$\mathrm{M}$} & ZPE $^{a}$ & ANO-MP2 $^{b}$ & ANO-QCISD $^{c}$ & ANO-QCISD(T) $^{c}$ \\
\hline $\mathrm{Zn}$ & -5.9 & -16.8 & -257.6 & -163.6 \\
$\mathrm{Cd}$ & -6.4 & +1.3 & -164.5 & -99.3 \\
$\mathrm{Hg} \mathrm{nr}$ & -6.2 & +14.2 & -148.0 & -85.6 \\
rele $^{e}$ & -7.1 & +63.4 & -12.5 & +18.7
\end{tabular}

${ }^{a}$ HF zero-point vibrational energy correction. ${ }^{b} / /$ ANO-MP2. $c / /$ ANO-QCISD. ${ }^{d}$ Nonrelativistic mercury pseudopotential. ' Quasirelativistic mercury pseudopotential.

and ca. $20 \mathrm{~kJ} \mathrm{~mol}^{-1}$ for $\mathrm{F}_{2}$ ), even for the computationally very demanding atomization energy in $\mathrm{KrF}_{2}$, indicates that the fluorine ANO valence basis-set used is adequate for a good correlation treatment. The agreement with experiment also is important for the discussion of the $\mathrm{F}_{2}$-elimination reactions (cf. below), and for the possible oxidation of $\mathrm{HgF}_{2}$ by $\mathrm{KrF}_{2}$ (cf. section $\mathrm{V}$ ).

Performance of MP2, QCISD, and QCISD(T) for Energies of $\mathrm{F}_{2}$-Elimination Reactions. The energies for the reactions $\mathrm{MF}_{4} \rightarrow$ $\mathrm{MF}_{2}+\mathrm{F}_{2}(\mathrm{M}=\mathrm{Zn}, \mathrm{Cd}, \mathrm{Hg})$ are shown in Table 9. Due to the much larger errors in the MP2 atomization energies for the tetrafluorides than for the difluorides (cf. above), MP2 strongly overestimates the stability of the former toward $\mathrm{F}_{2}$-elimination. Again, inclusion of relativistic effects for $\mathrm{Hg}$ decreases the discrepancy between MP2 and QCISD(T) (from ca. 100 to ca. $55 \mathrm{~kJ} \mathrm{~mol}^{-1}$ ). Similar results have been obtained by $\mathrm{Schwerdtfeger}$ et al. for the reaction $\mathrm{AuF}_{4}-\rightarrow \mathrm{AuF}_{2}-+\mathrm{F}_{2}$ (quasirelativistic and nonrelativistic ECP MP2, MP3, and MP4 results were compared). ${ }^{6 a}$

The contributions from triple excitations to the reaction energies for $\mathrm{F}_{2}$ elimination range from ca. $31 \mathrm{~kJ} \mathrm{~mol}^{-1}\left(\mathrm{HgF}_{4}(\mathrm{rel})\right)$ to $\mathrm{ca}$. $94 \mathrm{~kJ} \mathrm{~mol}^{-1}\left(\mathrm{ZnF}_{4}\right)$. The moderate contributions from triple substitutions for $\mathrm{HgF}_{4}$ (again reduced by relativistic effects) are responsible for the slight endothermicity obtained for the reaction $\mathrm{HgF}_{4} \rightarrow \mathrm{HgF}_{2}+\mathrm{F}_{2}$. Due to smaller nondynamical correlation contributions (cf. above) to the atomization energies for the difluorides than for the tetrafluorides, we expect a better treatment of electron correlation to increase the stability of the tetrafluorides compared to $\mathrm{MF}_{2}+\mathrm{F}_{2}$. Thus, given a small influence of spinorbit coupling (cf. section IV), our calculations probably underrather than overestimate the stability of the group 12 tetrafluorides towards $\mathrm{F}_{2}$ elimination. However, basis-set superposition errors might revert this trend (cf. below).

Influence of Basis-Set Superposition Errors (BSSE) on Stabilities of $\mathrm{HgF}_{4}$ and $\mathrm{HgF}_{2}$. To estimate the influence of BSSE on the ANO-QCISD(T) reaction energy for $\mathrm{HgF}_{4} \rightarrow \mathrm{HgF}_{2}+\mathrm{F}_{2}$, we have applied the counterpoise correction. ${ }^{31}$ Thus, the mercury atom has been calculated in the complete $\mathrm{HgF}_{4}$ and $\mathrm{HgF}_{2}$ molecular basis sets. Compared to the atomic basis, the mercury atom is stabilized by ca. $45.1 \mathrm{~kJ} \mathrm{~mol}^{-1}$ in the $\mathrm{HgF}_{4}$ basis, and by ca. $22.3 \mathrm{~kJ} \mathrm{~mol}^{-1}$ in the $\mathrm{HgF}_{2}$ basis. Open-shell ANO-QCI calculations of the fluorine atom in the $\mathrm{HgF}_{4}$ molecular basis have not been possible due to limitations of our computational resources. However, from ANO-MP2 calculations we estimate the counterpoise correction per fluorine atom in $\mathrm{HgF}_{4}, \mathrm{HgF}_{2}$,

(31) Boys, S. F.; Bernardi, F. Mol. Phys. 1970, 19, 553. 
Table 10. NPA Metal Net Charge $Q$, Metal Valence Populations and Relative NAO Contributions to $\mathrm{M}-\mathrm{F}$ Bonding in $\mathrm{MF}_{4}$ and $\mathrm{MF}_{2}$ $(\mathrm{M}=\mathrm{Zn}, \mathrm{Cd}, \mathrm{Hg})^{a}$

\begin{tabular}{lccccc}
\hline & & \multicolumn{3}{c}{ net populations } & \multirow{2}{*}{$\begin{array}{c}\text { M-F bonding } \\
\text { contribns }\end{array}$} \\
\cline { 2 - 5 } & $Q$ & $\mathrm{~s}$ & $\mathrm{p}$ & $\mathrm{d}$ & \\
\hline $\mathrm{ZnF}_{4}$ & 2.081 & 0.335 & 0.050 & 9.534 & $\mathrm{sp}^{0.37} \mathrm{~d}^{4.76}$ \\
$\mathrm{CdF}_{4}$ & 2.201 & 0.332 & 0.049 & 9.418 & $\mathrm{sp}^{0.14} \mathrm{~d}^{4.99}$ \\
$\mathrm{HgF}_{4}(\mathrm{nr})$ & 2.285 & 0.295 & 0.041 & 9.373 & $\mathrm{sp}^{0.14} \mathrm{~d}^{5.62}$ \\
$\mathrm{HgF}_{4}(\mathrm{rel})$ & 2.311 & 0.497 & 0.053 & 9.132 & $\mathrm{sp}^{0.18} \mathrm{~d}^{6.81}$ \\
$\mathrm{ZnF}_{2}$ & 1.756 & 0.260 & 0.027 & 9.957 & $\mathrm{sp}^{0.06} \mathrm{~d}^{0.03}$ \\
$\mathrm{CdF}_{2}$ & 1.763 & 0.270 & 0.024 & 9.943 & $\mathrm{sp}^{0.07} \mathrm{~d}^{0.04}$ \\
$\mathrm{HgF}_{2}$ (nr) & 1.803 & 0.227 & 0.020 & 9.946 & $\mathrm{sp}^{0.07} \mathrm{~d}^{0.03}$ \\
$\mathrm{HgF}_{2}$ (rel) & 1.590 & 0.568 & 0.024 & 9.982 & $\mathrm{sp}^{0.05} \mathrm{~d}^{0.13}$
\end{tabular}

- HF/ Basis A results. ${ }^{b}$ NPA contributions to M-F bonding NLMOs (based on an imposed "no-bond" NBO resonance structure, the metal NAO contributions to the least occupied F lone pair NLMO were analyzed).

and $F_{2}$ to be invariably ca. $3.4 \mathrm{~kJ} \mathrm{~mol}^{-1}$ (note that the MP2 and QCISD(T) BSSE estimates for the $\mathrm{Hg}$ atom are almost identical). Addition of these combined counterpoise corrections to the ANOQCISD(T) reaction energy $\left(+18.7 \mathrm{~kJ} \mathrm{~mol}^{-1}\right.$, cf. Table 9) would lead to a $\Delta E\left(\mathrm{HgF}_{4} \rightarrow \mathrm{HgF}_{2}+\mathrm{F}_{2}\right)$ of ca. $-4.1 \mathrm{~kJ} \mathrm{~mol}^{-1}$.

\section{The Influence of Relativistic Effects for $\mathrm{HgF}_{4}$ and $\mathrm{HgF}_{2}$}

Scalar Relativistic Effects on Bond Distances. The two bottom rows in Tables 3 and 4 compare the relativistic and nonrelativistic results for the calculated bond distances in $\mathrm{HgF}_{4}$ and in $\mathrm{HgF}_{2}$. As the relativistic effects (i.e. the differences between quasirelativistic and nonrelativistic pseudopotential results) are not the same for different treatments of electron correlation (cf. above), we will concentrate on the best calculations (ANO-QCISD, last columns). While both the bonds in $\mathrm{HgF}_{4}$ and in $\mathrm{HgF}_{2}$ are shortened by relativity, the contraction for the former (ca. 0.075 $\AA$ ) is smaller than that for the latter (ca. $0.112 \AA$ ). This is similar to previous results for gold(III) and gold(I) species. ${ }^{6}$ Using a simple atomic argument, these differences may be attributed to the different amount of s-orbital involvement in bonding ${ }^{5,6}$ (cf. last column in Table 10). While the bonding in the difluorides is dominated by the s-orbitals, the d-orbitals dominate for the tetrafluorides. Thus, for $\mathrm{HgF}_{4}$ the large relativistic contraction of the 6s-orbital (ca. $-0.25 \AA$ for $\Delta_{r}\langle r\rangle_{\mathrm{s}}$ in $\mathrm{Hg}\left({ }^{1} \mathrm{~S}\right)^{\mathrm{sc}}$ ) is diluted by the moderate relativistic expansion of the $5 \mathrm{~d}$-orbitals (weighted average for $\Delta_{r}\langle r\rangle_{d}$ in $\mathrm{Hg}\left({ }^{1} \mathrm{~S}\right)^{5 \mathrm{~s}}$ : ca. $\left.+0.02 \AA\right)$. The relativistic bond contractions bring the $\mathrm{Hg}-\mathrm{F}$ distances close to the corresponding $\mathrm{Cd}-\mathrm{F}$ distances. Note that different interpretations of relativistic effects on bond lengths are possible. ${ }^{\mathrm{Sd}, 32}$

Scalar Relativistic Effects on Stability. In spite of the relativistic bond contraction (cf. above), relativistic effects decrease the atomization energies both for $\mathrm{HgF}_{4}$ and for $\mathrm{HgF}_{2}$ (cf. Table 7). However, this relativistic destabilization is significantly larger (ca. $157 \mathrm{~kJ} \mathrm{~mol}^{-1}$, ca. $25 \%$ ) for $\mathrm{HgF}_{2}$ than for $\mathrm{HgF}_{4}$ (ca. $53 \mathrm{~kJ}$ $\mathrm{mol}^{-1}, \mathrm{ca} .8 \%$ ). Schwerdtfeger et al. found a relativistic decrease of the atomization energy in AuF (by ca. $60 \mathrm{~kJ} \mathrm{~mol}^{-1}$ ), but a relativistic increase for $\mathrm{AuF}_{3}$ (by ca. $143 \mathrm{~kJ} \mathrm{~mol}^{-1}$ ). ${ }^{6 \mathrm{a}}$ However, the latter result is based on Hartree-Fock calculations. Indeed, we obtain a relativistic increase in the atomization energy of $\mathrm{HgF}_{4}$ (by ca. $122 \mathrm{~kJ} \mathrm{~mol}^{-1}$ ) at the $\mathrm{HF} /$ basis-B level. This is an artefact due to the better performance of HF (i.e. reduced nondynamical correlation effects, cf. section III) in the quasirelativistic compared to the nonrelativistic ECP regime. To see whether the results of Schwerdtfeger et al. for $\mathrm{AuF}_{3}$ are also due to the neglect of electron correlation, we have calculated the $\mathrm{AuF}_{3}$ atomization energy at the nonrelativistic and quasirelativistic MP2/basis-B and QCISD/basis-B levels ${ }^{33}$ using the correspond-

(32) Schwarz, W. H. E. Phys. Scr. 1987, 36, 403.

(33) The 19-valence-electron pseudopotentials and $(8 \mathrm{~s} 7 \mathrm{p6d}) /[6 \mathrm{~s} 5 \mathrm{p} 3 \mathrm{~d}]$ valence basis sets for Au have been taken from ref 11 . A set of f-functions ( $=1.1447$ ) was added (cf. ref $6 \mathrm{~b}$ ). ing HF-optimized structures of ref $6 \mathrm{a}$. The quasirelativistic and nonrelativistic QCISD (MP2) results are 582.6 (661.4) and 444.2 (559.3) $\mathrm{kJ} \mathrm{mol}^{-1}$, respectively. Thus, as found by Schwerdtfeger et al., ${ }^{6 \mathrm{a}} \mathrm{AuF}_{3}$ is indeed stabilized by scalar relativistic effects, in contrast to $\mathrm{HgF}_{4}$. The better agreement between MP2 and QCISD for $\mathrm{AuF}_{3}$ compared to $\mathrm{HgF}_{4}$ also is an interesting result.

These different contributions of relativity to the atomization energies may be rationalized by a simple picture (cf. above for the interpretation of bond length contractions) using the metal s- and d-orbital participation in bonding (cf. Table 10), and bond polarity. In $\mathrm{HgF}_{2}$ (as in $\mathrm{AuF}$ ), ${ }^{6}$ the relativistically increased 6s-ionization energy leads to a bond destabilization, as the bonding is mainly of the type $\mathrm{Hg}^{+2}\left(\mathrm{~F}^{-}\right)_{2}$. In $\mathrm{HgF}_{4}$, this destabilization is diluted by the considerable 5d-orbital contribution to bonding (Table 10). In $\mathrm{AuF}_{3}$, the relative d-orbital participation in bonding is even larger-hence, the relativistic stabilization. The large relativistic destabilization in $\mathrm{HgF}_{2}$ due to the relativistically increased 6s-ionization potential of mercury certainly is of general importance for the well-known reluctance ${ }^{1-3}$ of $\mathrm{Hg}$ (II) to form strong bonds to electronegative elements like fluorine or oxygen.

The differential relativistic stabilization of $\mathrm{HgF}_{4}$ vs $\mathrm{HgF}_{2}+$ $F_{2}$ may be inferred from Table 9 . Without relativity, the $F_{2-}$ elimination reaction would be considerably exothermic, similar to the corresponding reaction for $\mathrm{CdF}_{4}$. However, this stabilization of oxidation state IV is due to the large relativistic destabilization of $\mathrm{HgF}_{2}$ and not to a relativistic stabilization of $\mathrm{HgF}_{4}$ itself? Similar considerations may be important for the discussion of the relative stability of different oxidation states in compounds of other heavy transition metals.

Influence of Spin-Orbit Coupling on Relative Stabilities. To evaluate the importance of spin-orbit (SO) coupling on the stability of $\mathrm{HgF}_{4}$ vs $\mathrm{HgF}_{2}+\mathrm{F}_{2}$, we have carried out relativistic 2-component SCF calculations with the program RELMOL. ${ }^{34}$ A 20-valence-electron pseudopotential, slightly different from that used throughout the remainder of this study, with a $8 \mathrm{~s} 7 \mathrm{p} 6 \mathrm{~d}$ valence basis for $\mathrm{Hg}^{35}$ and a $6 \mathrm{~s} 6 \mathrm{p}$ valence basis for fluorine, $15 \mathrm{a}$ has been employed. The two-component single-point SCF calculations were carried out at the one-component ANO-QCISD optimized geometries (cf. Tables 3 and 4).

The influence of SO coupling is most conveniently discussed as contribution to reaction energies: Spin-orbit coupling stabilizes $\mathrm{HgF}_{4}$ by ca. $11.1 \mathrm{~kJ} \mathrm{~mol}^{-1}$ with respect to $\mathrm{HgF}_{2}+\mathrm{F}_{2} . \mathrm{HgF}_{2}$ is further stabilized by ca. $3.9 \mathrm{~kJ} \mathrm{~mol}^{-1} \mathrm{vs} \mathrm{Hg}+\mathrm{F}_{2}$. Thus, spinorbit coupling in $\mathrm{HgF}_{4}$ and in $\mathrm{HgF}_{2}$ is relatively small and favors the tetrafluoride.

\section{The Stability of $\mathrm{MF}_{4}$ vs. $\mathrm{MF}_{2}(\mathrm{M}=\mathrm{Zn}, \mathrm{Cd}, \mathrm{Hg})$}

The atomization energies given in Table 7 show that the general order of average $\mathrm{M}-\mathrm{F}$ bond strength is $\mathrm{Zn}>\mathrm{Cd}>\mathrm{Hg}$ (the relative position of $\mathrm{Cd}$ and $\mathrm{Hg}$ being due to relativistic effects), both in the difluorides and in the tetrafluorides. This agrees with the general observation that $\mathrm{M}-\mathrm{X}$ bond strengths for a given substituent $\mathrm{X}$ tend to decrease down group 12.2 However, the particularly strong bonds in the zinc and cadmium difluorides (QCISD(T) average binding energies are ca. 375 and $318 \mathrm{~kJ}$ $\mathrm{mol}^{-1}$ in $\mathrm{ZnF}_{2}$ and $\mathrm{CdF}_{2}$, respectively) make the existence of the corresponding tetrafluorides extremely unlikely. The QCISD(T) energies for elimination of $\mathrm{F}_{2}$ from $\mathrm{ZnF}_{4}$ and $\mathrm{CdF}_{4}$ are -164 and $-99 \mathrm{~kJ} \mathrm{~mol}^{-1}$, respectively (cf. Table 7), and even the oxidation of gaseous monomeric $\mathrm{ZnF}_{2}$ by fluorine atoms is calculated to be endothermic by ca. $10 \mathrm{~kJ} \mathrm{~mol}^{-1}$. Even if the stability of the zinc and cadmium tetrafluorides might come out slightly larger

(34) RELMOL, 2- and 4-component relativistic SCF and MRCI program Hafner, P.; Esser, M.; Schwarz, W. H. E.; Mark, F.; Schwerdtfeger, P.; Dolg, M., cf. Hafner, P.; Schwarz, W. H. E. Chem. Phys. Lett. 1979, 65,357 .

(35) Häussermann, U.; Dolg, M.; Stoll, H.; Preuss, H.; Schwerdtfeger, P. Pitzer, R. M. Mol. Phys. 1993, 78, 1211 
Table 11. Calculated Reaction Energies $\left(\mathrm{kJ} \mathrm{mol}^{-1}\right)$ for $\mathrm{MF}_{2}+\mathrm{KrF}_{2}$ $\rightarrow \mathrm{MF}_{4}+\mathrm{Kr}$

\begin{tabular}{lcccc}
\hline $\mathrm{M}$ & ZPE $^{a}$ & ANO-MP2 $^{b}$ & ANO-QCISD $^{c}$ & ANO-QCISD(T) $^{c}$ \\
\hline $\mathrm{Zn}$ & +2.1 & -30.4 & +164.4 & +88.1 \\
$\mathrm{Cd}$ & +2.6 & -48.5 & +77.2 & +23.9 \\
$\mathrm{Hg} \mathrm{nr}^{d}$ & +2.4 & -61.4 & +54.7 & +10.1 \\
rel $^{e}$ & +3.3 & -111.1 & -80.8 & -94.2
\end{tabular}

a HF zero-point-vibrational energy correction. $b / /$ ANO-MP2. $c / /$ ANO-QCISD. ${ }^{d}$ Nonrelativistic mercury pseudopotential. ${ }^{\bullet}$ Quasirelativistic mercury pseudopotential.

at still higher theoretical levels, the existence of these species is highly improbable.

In contrast, molecular $\mathrm{HgF}_{4}$ may be stable or only slightly endothermic with respect to $\mathrm{HgF}_{2}+\mathrm{F}_{2}$, due to the influence of relativistic effects (see above): The best ANO-QCISD(T) calculations (Table 9) corrected for spin-orbit coupling (cf. section IV), zero-point vibrational energy corrections (Table 9), and basisset superposition errors (cf. section III) yield a reaction enthalpy $\left(\Delta H^{\circ}\right)$ of ca. $-0.1 \mathrm{~kJ} \mathrm{~mol}^{-1}$. We estimate that a more complete treatment of electron correlation would yield a slightly positive $\Delta H^{\circ}$ (cf. section III). Note that lattice energy contributions for $\mathrm{HgF}_{2}$ will cause a differential stabilization of $\mathrm{HgF}_{2}+\mathrm{F}_{2}$ vs $\mathrm{HgF}_{4}$ in the solid state (cf. Section VIII).

Possible Preparation Routes for $\mathbf{H g F}_{4}$. Krypton difluoride, $\mathrm{KrF}_{2}$, is a well-known endothermic fluorine compound that has been used as an extremely reactive agent to obtain unusually high oxidation states, e.g. in the preparation of $\mathrm{AuF}_{5 .}{ }^{36}$ Table 11 shows the reaction energies calculated at various theoretical levels for the oxidation of $\mathrm{HgF}_{2}$ by $\mathrm{KrF}_{2}$. For comparison, results for $\mathrm{ZnF}_{2}$ and $\mathrm{CdF}_{2}$, as well as nonrelativistic results for $\mathrm{HgF}_{2}$, are also included.

The discrepancies between the MP2, QCISD, and QCISD(T) atomization energies for the tetrafluorides (cf. Table 7 and section III) are carried over into the energies of the oxidation reactions of $\mathrm{ZnF}_{2}, \mathrm{CdF}_{2}$, and "nonrelativistic" $\mathrm{HgF}_{2}$ (cf. Table 11). In all these three cases (top three rows) the best results (ANO-QCISD$(T))$ indicate an endothermic reaction, significantly so for $\mathrm{Zn}$. In calculations using the relativistic mercury pseudopotential, the compensation between the MP2 vs. QCISD vs. QCISD(T) differences in the atomization energies of $\mathrm{HgF}_{2}, \mathrm{HgF}_{4}$, and $\mathrm{KrF}_{2}$ (cf. Tables 7 and 8 ) is much better (cf. last row in Table 11), and the different levels agree reasonably well for the oxidation energy. There is little doubt that the reaction $\mathrm{HgF}_{2}+\mathrm{KrF}_{2} \rightarrow \mathrm{HgF}_{4}+$ $\mathrm{Kr}$ is significantly exothermic (by ca. $100 \mathrm{~kJ} \mathrm{~mol}^{-1}$ ). Thus, the preparation of $\mathrm{HgF}_{4}$ along this route appears feasable. A major problem is that the reaction has to be carried out under conditions where the lattice energy of $\mathrm{HgF}_{2}$ is unimportant (cf. discussion in section VIII) but $\mathrm{KrF}_{2}$ is still stable. This points either to a molecular beam experiment with subsequent mass-spectrometric characterization or matrix isolation of the products or to a lowtemperature solvent variant of the reaction. Apparently, there has already been an attempt to conduct the reaction in liquid $\mathrm{HF}$, but no product could be isolated. ${ }^{37}$ As the reaction $\mathrm{HgF}_{2}+2 \mathrm{~F}$ $\rightarrow \mathrm{HgF}_{4}$ is exothermic by ca. $150 \mathrm{~kJ} \mathrm{~mol}^{-1}$, one might also speculate about a photochemical reaction involving fluorine atoms. As our calculations indicate that the reaction $\mathrm{HgF}_{2}+\mathrm{F}_{2} \rightarrow \mathrm{HgF}_{4}$ may be slightly exothermic (cf. above), even the direct fluorination of $\mathrm{HgF}_{2}$ under suitable conditions may not be ruled out.

VI. Electronic Structure and Bonding in $\mathbf{M F}_{4}$ and $\mathbf{M F}_{2}(\mathbf{M}=$ $\mathrm{Zn}, \mathrm{Cd}, \mathbf{H g}$ )

For an understanding of the different stabilities of $\mathrm{ZnF}_{4}, \mathrm{CdF}_{4}$, and $\mathrm{HgF}_{4}$, it is useful to compare the electronic structures of the group 12 di- and tetrafluorides. We have employed the natural

(36) See, e.g.: Holloway, J. H.; Schrobilgen, G. J. J. Chem. Soc., Chem. Commun. 1975, 78.

(37) Müller, B. Personal communication.
Table 12. Calculated Harmonic Vibrational Frequencies for $\mathrm{HgF}_{4}^{a}$

\begin{tabular}{cccc}
\hline symmetry & $\omega, \mathrm{cm}^{-1}$ & IR active & Raman active \\
\hline $\mathrm{B}_{2 \mathrm{u}}$ & 179 & yes & no \\
$\mathrm{A}_{2 \mathrm{u}}$ & 233 & yes & no \\
$\mathrm{B}_{2 \mathrm{~g}}$ & 252 & no & yes \\
$\mathrm{E}_{\mathrm{u}}$ & 261 & yes & no \\
$\mathrm{B}_{1 \mathrm{~g}}$ & 650 & no & yes \\
$\mathrm{A}_{1 \mathrm{~g}}$ & 652 & no & yes \\
$\mathrm{E}_{\mathrm{u}}$ & 721 & yes & no
\end{tabular}

${ }^{a} \mathrm{HF} /$ basis-A results.

population analysis (NPA) and natural bond orbital (NBO) methods. ${ }^{38}$ Table 10 gives the metal charges, the metal net $n \mathrm{~s}$, $n$, and $(n-1) d$ populations, and an estimate of the relative metal AO contributions to covalent bonding. The latter estimate is based on the analysis of natural atomic orbital (NAO) contributions to natural localized molecular orbitals (NLMO). These in turn have been constructed from a natural bond orbital (NBO) ionic "Lewis structure" $\left(\mathrm{Hg}^{4+}+4 \mathrm{~F}^{-}\right)$with no covalent $\mathrm{M}-\mathrm{F}$ bonding. The numbers given in the last column of Table 10 thus are the relative contributions from metal $s, p$, and $d$ orbitals to the resulting least-occupied fluorine lone-pair NLMO (which indeed is $\mathrm{M}-\mathrm{F} \sigma$-bonding). $\pi$-Bonding contributions are negligible in all cases.

While the NPA metal charges $Q$ in $\mathrm{ZnF}_{2}, \mathrm{CdF}_{2}$, and $\mathrm{HgF}_{2}$ (nonrelativistic calculation) are close to 1.8 (Table 10), relativity reduces this value to ca. 1.6 for $\mathrm{HgF}_{2}$. This is due to the relativistic increase of the first two ionization energies in mercury (cf. Table 1 and Introduction), which disfavors an ionic configuration, $\mathrm{Hg}^{2+}\left(\mathrm{F}^{-}\right)_{2}$, and indeed destabilizes the bonds in $\mathrm{HgF}_{2}$ appreciably (cf. section IV). The little covalent bonding present in the difluorides is due to the metal s-orbitals (and largely fluorine p-orbitals) with only marginal metal p-or d-orbital participation (a small relativistic increase of the d-contributions is observed for $\mathrm{HgF}_{2}$; see Table 10 ).

In contrast to $\mathrm{HgF}_{2}$, the metal charge in $\mathrm{HgF}_{4}$ is affected only slightly by relativity and is similar to the charges calculated for $\mathrm{ZnF}_{4}$ and $\mathrm{CdF}_{4}$. An increase of the metal charge by only ca. 0.2-0.7 electron (from ca. 1.6-1.8 to ca. 2.2-2.3 electrons) from $\mathrm{M}$ (II) to $\mathrm{M}(\mathrm{IV})$ indicates significant covalent bonding contributions for the tetrafluorides, as might be expected for a metal in formal oxidation state +IV. However, the distribution of the metal valence population into $n \mathrm{~s}, n \mathrm{p}$, and $(n-1) \mathrm{d}$ NAOs, and the relative contributions of the metal orbitals to the $\mathrm{M}-\mathrm{F}$ bonds differ appreciably for the tetrafluorides. The ionization of s-electrons is less pronounced and that of d-electrons is more pronounced for $\mathrm{HgF}_{4}$ than for its lighter congeners, particularly in the quasirelativistic calculation, $\mathrm{HgF}_{4}(\mathrm{rel})$. Consequently, the $\mathrm{d} / \mathrm{s}$ ratio of the metal NAO contributions to $\mathrm{M}-\mathrm{F}$ bonding is larger for $\mathrm{HgF}_{4}$ (ca. 6.8) than for $\mathrm{ZnF}_{4}$ and $\mathrm{CdF}_{4}$ (ca. 4.8-5.0). Comparison with the nonrelativistic $\mathrm{HgF}_{4}$ results in Table 10 shows that this is to a large extent due to relativity.

The significant d-orbital contributions to bonding indeed characterize the tetrafluorides as genuine transition metal compounds with a formal $d^{8}$ configuration, whereas the difluorides (even $\mathrm{HgF}_{2}$ ) may be safely regarded as rather ionic $\mathrm{d}^{10}$ main group species.

\section{Harmonic Vibrational Frequencies for $\mathrm{HgF}_{4} \mathrm{HgF}_{2}$, and $\left(\mathrm{HgF}_{2}\right)_{2}$}

Vibrational spectroscopy may be an important method to identify and characterize $\mathrm{HgF}_{4}$ once obtained. To facilitate the identification, we have performed harmonic vibrational frequency analyses (at the $\mathrm{HF}$ /basis-A level) for $\mathrm{HgF}_{4}$ and $\mathrm{HgF}_{2}$, and for the $\mathrm{HgF}_{2}$ dimer. The results are listed in Tables $12-14$. The

(38) (a) Reed, A. E.; Weinstock, R. B.; Weinhold, F. J. Chem. Phys. 1985 83, 735. (b) Reed, A. E.; Weinhold, F. J. Chem. Phys. 1985, 83, 1736. (c) Reed, A. E.; Curtiss, L. A.; Weinhold, F. Chem. Rev. 1988, 88, 899. 
Table 13. Comparison of Experimental Frequencies and Calculated Harmonic Vibrational Frequencies for $\mathrm{HgF}_{2}{ }^{a}$

\begin{tabular}{ccccc}
\hline symmetry & $\omega_{\text {calcd, }} \mathrm{cm}^{-1}$ & $\omega_{\text {expl1 }} \mathrm{cm}^{-1}$ & IR active & Raman active \\
\hline$\Pi_{\mathrm{u}}$ & 159 & 170 & yes & no \\
$\sum_{\mathfrak{g}}$ & 577 & 568 & no & yes \\
$\sum_{\mathrm{v}}$ & 648 & 642 & yes & no
\end{tabular}

- HF/basis-A results. ' Given, A.; Loewenschuss, A. J. Chem. Phys. 1980, 72, 3809.

Table 14. Calculated Harmonic Vibrational Frequencies for $\left(\mathrm{HgF}_{2}\right)_{2}{ }^{2}$

\begin{tabular}{cccc}
\hline symmetry & $\omega, \mathrm{cm}^{-1}$ & IR active & Raman active \\
\hline $\mathbf{A}_{\mathbf{u}}$ & 51 & yes & no \\
$\mathbf{A}_{\mathbf{g}}$ & 83 & no & yes \\
$\mathbf{A}_{\mathbf{g}}$ & 86 & no & yes \\
$\mathbf{B}_{\mathbf{u}}$ & 91 & yes & no \\
$\mathbf{B}_{\mathbf{g}}$ & 126 & no & yes \\
$\mathbf{A}_{\mathbf{u}}$ & 168 & yes & no \\
$\mathbf{B}_{\mathbf{u}}$ & 209 & yes & no \\
$\mathbf{A}_{\mathbf{g}}$ & 276 & no & yes \\
$\mathbf{A}_{\mathbf{g}}$ & 479 & no & yes \\
$\mathbf{B}_{\mathfrak{u}}$ & 522 & yes & no \\
$\mathbf{B}_{\mathbf{u}}$ & 606 & yes & no \\
$\mathbf{A}_{\mathbf{g}}$ & 611 & no & yes
\end{tabular}

a HF/basis-A results.

Table 15. HF Zero-Point Vibrational Energy Corrections ( $\mathrm{kJ} \mathrm{mol}^{-1}$ ) for Various Species Considered ${ }^{a}$

\begin{tabular}{lrlc}
\hline species & ZPE & species & ZPE \\
\hline $\mathrm{ZnF}_{2}$ & 10.2 & $\mathrm{HgF}_{3}-$ rel & 9.6 \\
$\mathrm{CdF}_{2}$ & 8.6 & $\mathrm{HgF}_{4}^{-2}$ rel & 11.3 \\
$\mathrm{HgF}_{2} \mathrm{nr}$ & 7.7 & $\mathrm{HgF}_{5}$ rel & $25.9^{b}$ \\
$\mathrm{rel}_{\text {rel }}$ & 9.6 & $\mathrm{HgF}_{6}{ }^{-2}$ rel & 27.7 \\
$\mathrm{ZnF}_{4}$ & 23.2 & $\mathrm{KrF}_{2}$ & 10.9 \\
$\mathrm{CdF}_{4}$ & 22.1 & $\mathrm{~F}_{2}$ & 7.1 \\
$\mathrm{HgF}_{4} \mathrm{nr}$ & 20.5 & & \\
rel & 23.4 & &
\end{tabular}

- Basis-A results with quasirelativistic (rel) or nonrelativistic (nr) $\mathrm{Hg}$ Pseudopotential. ${ }^{b}$ In $C_{40}$ symmetry.

$\mathrm{HgF}_{2}$ dimer might be one of the species present in a gas-phase molecular beam experiment. Its structure and stability with respect to $2 \mathrm{HgF}_{2}$ will be discussed in section VIII. More detailed computational results on this species will be presented elsewhere as part of a study on mercury(II) coordination. ${ }^{39}$ The frequencies calculated for $\mathrm{HgF}_{2}$ are in good agreement with experiment (cf. Table 13). The HF frequencies calculated for $\mathrm{AuF}_{4}-$ at a basisset level similar to that used in the present study also agree with experiment to within ca. $10 \mathrm{~cm}^{-1} \cdot{ }^{6 a}$ We expect comparable accuracy for $\mathrm{HgF}_{4}$.

Due to the high symmetry present, the IR and Raman spectra of $\mathrm{HgF}_{4}$ can contain no more than 4 and 3 lines, respectively. Moreover, the vibrational wavenumbers of $\mathrm{HgF}_{2}$ and $\left(\mathrm{HgF}_{2}\right)_{2}$ differ considerably from those of $\mathrm{HgF}_{4}$ (compare Tables 12-14), particularly in the experimentally most accessible range above ca. $300 \mathrm{~cm}^{-1}$. This should facilitate the identification of $\mathrm{HgF}_{4}$ by means of vibrational spectroscopy. Results of the harmonic vibrational frequency analyses for $\mathrm{HgF}_{5}^{-}, \mathrm{HgF}_{6}{ }^{-2}, \mathrm{HgF}_{3}-, \mathrm{HgF}_{4}{ }^{-2}$, and $\mathrm{KrF}_{2}$ are available from the authors upon request. The zeropoint vibrational energies calculated for these species, the group 12 di- and tetrafluorides, and $F_{2}$ are given in Table 15 . They have been employed to calculate the zero-point vibrational energy corrections for the reaction energies given throughout this paper (Tables 7, 8, 11, and 16-18).

VIII. Stabilization of $\mathbf{H g F}_{4}$ vs $\mathbf{H g F}_{2}$ by Anionic Complexation or by Aggregation?

Fluoro Complexes: The Model Species $\mathrm{HgF}_{5}-\mathrm{HgF}_{6}{ }^{2-}, \mathrm{HgF}_{3}{ }^{-}$, and $\mathrm{HgF}_{4}{ }^{2}$. Formation of anionic complexes often is a means

(39) Kaupp, M.; v. Schnering, H. G. Inorg. Chem., in press.
Table 16. Relative Energies of $C_{40}$ and $D_{3 h}$ Structures for $\mathrm{HgF}_{5}$ $\left.(\mathrm{kJ} \mathrm{mol})^{-1}\right)^{a}$

\begin{tabular}{ccccc}
\hline & ZPE $^{b}$ & HF/basis-A & MP2/basis-B & QCISD/basis-B \\
\hline$C_{4 v}$ & 25.9 & 0.0 & 0.0 & 0.0 \\
$D_{3 h}$ & 23.8 & +45.6 & +10.0 & +22.6
\end{tabular}

a Calculated for the MP2/basis-A optimized structures (cf. Figure 2). ${ }^{b} \mathrm{HF} /$ basis-A zero-point vibrational energy.

Table 17. Calculated Fluoride Attachment Energies $\left(\mathrm{kJ} \mathrm{mol}^{-1}\right)^{a}$

\begin{tabular}{|c|c|c|c|c|}
\hline reaction & $\mathrm{ZPE}^{b}$ & HF & MP2 & QCISD \\
\hline $\begin{array}{l}\mathrm{HgF}_{2}+\mathrm{F}^{-} \rightarrow \mathrm{HgF}_{3}^{-} \\
\mathrm{HgF}_{3}^{-}+\mathrm{F}^{-} \rightarrow \mathrm{HgF}_{4}^{2-} \\
\mathrm{HgF}_{4}+\mathrm{F}^{-} \rightarrow \mathrm{HgF}_{5}^{-} \\
\mathrm{HgF}_{5}^{-}+\mathrm{F}^{-} \rightarrow \mathrm{HgF}_{6}^{2-}\end{array}$ & $\begin{array}{l}+0.4 \\
+1.7 \\
+2.5 \\
+1.8\end{array}$ & $\begin{array}{l}-228.4 \\
+148.5 \\
-231.8 \\
+417.9\end{array}$ & $\begin{array}{l}-199.1 \\
+167.8 \\
-236.8 \\
+364.8^{c}\end{array}$ & $\begin{array}{l}-208.4 \\
+166.9 \\
-234.7 \\
+400.4^{c}\end{array}$ \\
\hline
\end{tabular}

Table 18. Comparison of QCISD/Basis-B//MP2/Basis-A $F_{2}$ Elimination Energies $\Delta E_{\mathrm{f}}\left(\mathrm{kJ} \mathrm{mol}^{-1}\right)$ for $\mathrm{HgF}_{4}, \mathrm{HgF}_{5}$, and $\mathrm{HgF}_{6}{ }^{2-}$

\begin{tabular}{cc}
\hline \multicolumn{1}{c}{ reaction } & $\Delta E_{\mathrm{f}}$ \\
\hline $\mathrm{HgF}_{4} \rightarrow \mathrm{HgF}_{2}+\mathrm{F}_{2}$ & -32.6 \\
$\mathrm{HgF}_{5} \rightarrow \mathrm{HgF}_{3}+\mathrm{F}_{2}$ & -5.9 \\
$\mathrm{HgF}_{6}{ }^{-2} \rightarrow \mathrm{HgF}_{4}^{2-}+\mathrm{F}_{2}$ & $-249.8^{a}$
\end{tabular}

$a$ Mercury 5s and 5p orbitals not correlated.
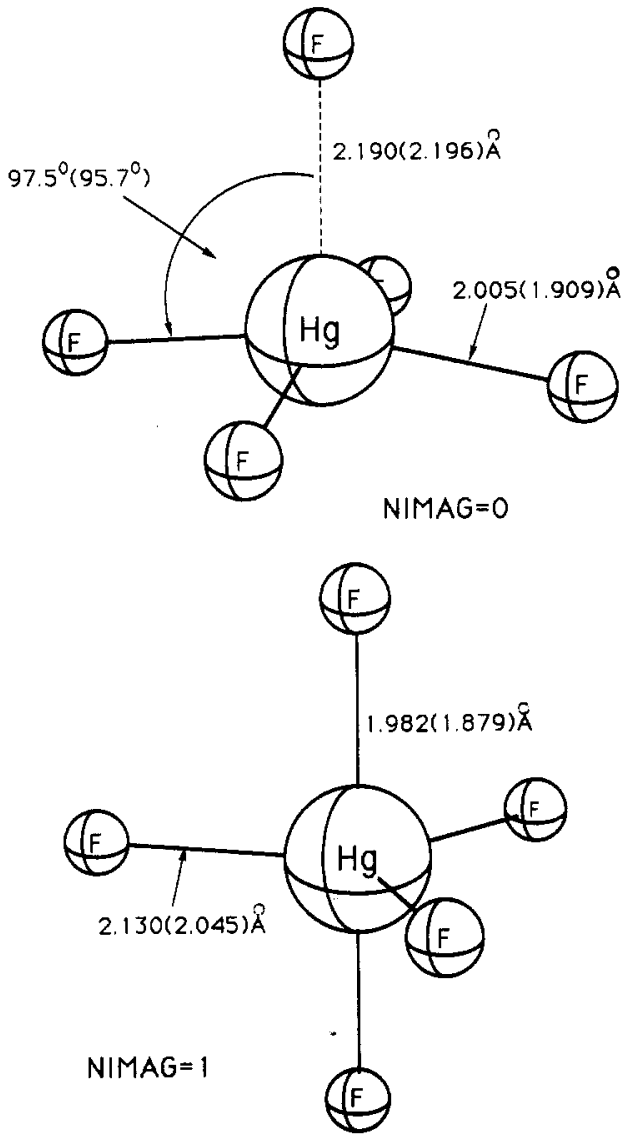

Figure 2. Optimized MP2(HF)/basis-A structures for $\mathrm{HgF}_{5}$ : : (a, top) $C_{4 v}$ structure (minimum); (b, bottom) $D_{3 h}$ structure (transition state).

to stabilize metal species in high oxidation states. ${ }^{3}$ Therefore $\mathrm{HgF}_{5}-$ and $\mathrm{HgF}_{6}{ }^{2-}$ have been considered. For the former, both the trigonal bipyramidal $\left(D_{3 h}\right)$ and the square pyramidal $\left(C_{4 v}\right)$ structures have been optimized (Figure 2). At all theoretical levels we find the $C_{4 v}$ arrangement to be slightly more stable than the $D_{3 h}$ structure (at the HF level, the $D_{3 h}$ form is a transition state with one imaginary frequency, whereas the $C_{4 v}$ form is a minimum). The best calculated value for the energy difference is ca. $20 \mathrm{~kJ} \mathrm{~mol}^{-1}$ (cf. Table 16). As indicated by the bond lengths, 


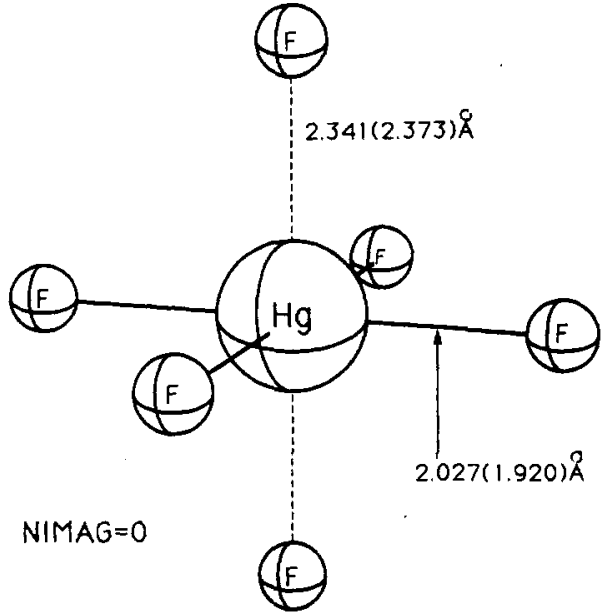

Figure 3. Optimized MP2(HF)/basis-A structures for $\mathrm{HgF}_{6}{ }^{2-}$ in $D_{4 h}$ symmetry (HF minimum).

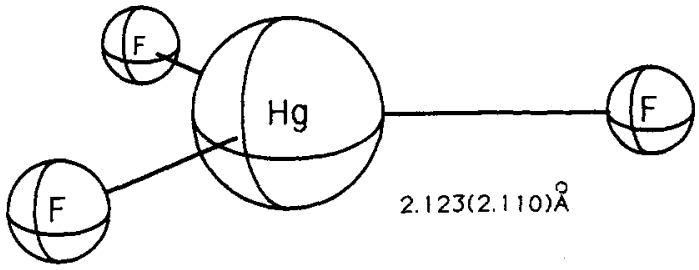

NIMAG $=0$

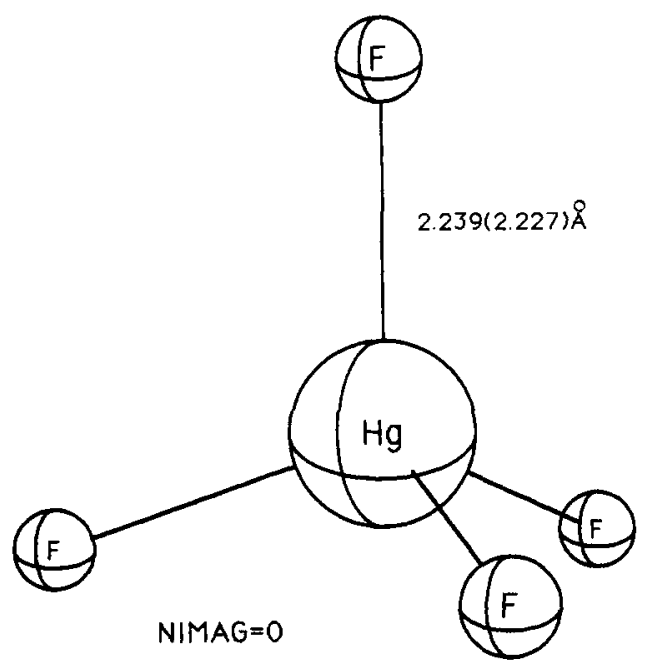

Figure 4. Optimized MP2(HF)/basis-A minimum structures for $\mathrm{HgF}_{3}-$ and $\mathrm{HgF}_{4}{ }^{2-}:$ (a, top) $\mathrm{HgF}_{3}$ - in $D_{3 h}$ symmetry; (b, bottom) $\mathrm{HgF}_{4}{ }^{2-}$ in $T_{d}$ symmetry.

the apical secondary $\mathrm{Hg}-\mathrm{F}$ bond in the $C_{4 v}$ structure is considerably less effective than the primary basal bonds (cf. Figure 2). The $\mathrm{F}_{\mathrm{ap}} \mathrm{HgF}_{\text {bas }}$ angle is rather close to $90^{\circ}$. Interestingly, the $D_{3 h}$ structure exhibits shorter axial than equatorial bonds. As indicated by the rather long secondary bonds in $\mathrm{HgF}_{6}{ }^{2-}$ (Figure 3 ), binding of a second fluoride ion appears to be still much less effective than that of the first (see below). In contrast, the anionic $\mathrm{Hg}$ (II) fluoride complexes $\mathrm{HgF}_{3}$ - and $\mathrm{HgF}_{4}{ }^{2-}$ feature structures with identical $\mathrm{Hg}-\mathrm{F}$ bonds (cf. Figure 4), although longer than those in $\mathrm{HgF}_{2}$ (cf. Table 4). Both the $D_{3 h}$ structure for $\mathrm{HgF}_{3}$ and the $T_{d}$ structure for $\mathrm{HgF}_{4}{ }^{2-}$ are minima on their HF/basis-A potential energy surfaces. However, to our knowledge none of these complex anions of mercury(II) fluoride has been observed experimentally.

Table 17 summarizes the QCISD, MP2, and HF results (basisB) for the energy gained by the attachment of a first and a second fluoride ion to $\mathrm{HgF}_{4}$ or to $\mathrm{HgF}_{2}$. While the first fluoride ion is added exothermically, the second addition is endothermic, as
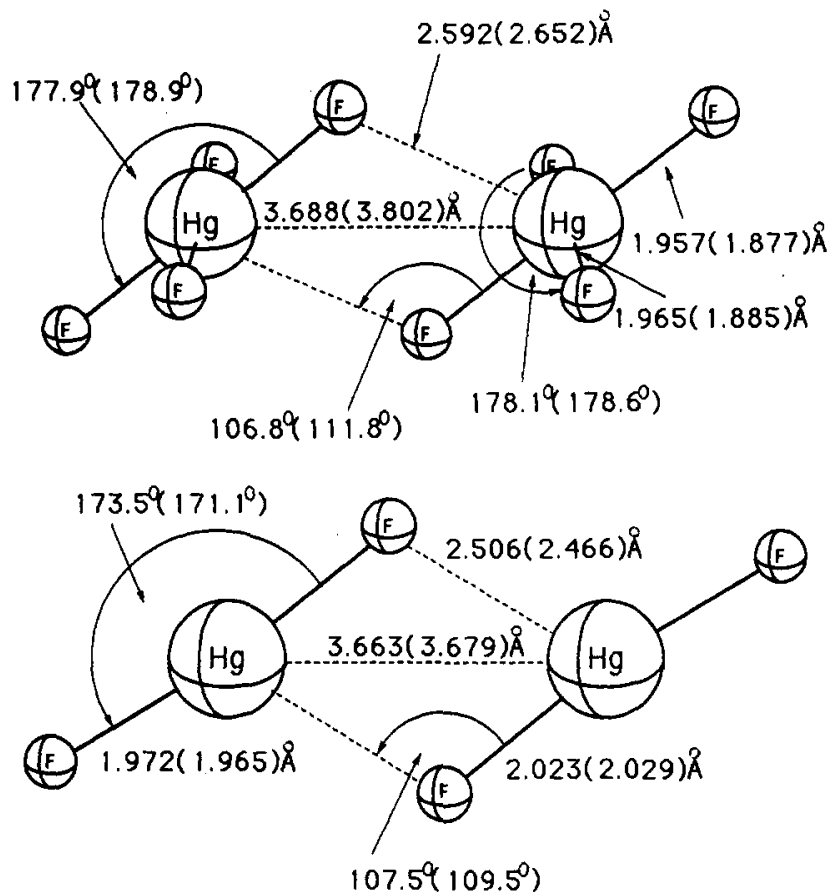

Figure 5. Optimized MP2(HF)/basis-A structures for $\left(\mathrm{HgF}_{4}\right)_{2}$ and $\left(\mathrm{HgF}_{2}\right)_{2}$ in $\mathrm{C}_{2 h}$ symmetry: (a, top) $\left(\mathrm{HgF}_{4}\right)_{2} ;\left(\mathrm{b}\right.$, bottom) $\left(\mathrm{HgF}_{2}\right)_{2}$ (HF minimum).

expected for the free anions. Most importantly, the first addition is slightly more exothermic for $\mathrm{HgF}_{4}$ than for $\mathrm{HgF}_{2}$, but the second fluoride addition is far more endothermic for $\mathrm{HgF}_{5}$ than for $\mathrm{HgF}_{3}-$. Thus, the result suggested by the structures of the anions (Figures 2-4) is borne out by the fluoride attachment energies: The stabilization of $\mathrm{Hg}$ (II) by anionic complexation is larger than for $\mathrm{Hg}(\mathrm{IV})$. The consequences of the fluoride attachment energies given in Table 17 for the elimination of $F_{2}$ from $\mathrm{HgF}_{4}, \mathrm{HgF}_{5}$, or $\mathrm{HgF}_{6}{ }^{-2}$ are shown in Table 18. While $\mathrm{F}_{2}$-elimination from $\mathrm{HgF}_{5}$ - is slightly less favorable than for $\mathrm{HgF}_{4}$ (note the inferior theoretical level compared to the data given in Table 9), addition of a second fluoride ion strongly favors the +II state.

Aggregation: Comparison of $\left(\mathrm{HgF}_{4}\right)_{2}$ and $\left(\mathrm{HgF}_{2}\right)_{2}$. As a first step toward modeling the aggregation of $\mathrm{HgF}_{4}$ in the condensed phase, in comparison with $\mathrm{HgF}_{2}$, we have studied the dimers $\left(\mathrm{HgF}_{4}\right)_{2}$ and $\left(\mathrm{HgF}_{2}\right)_{2}$ at the $\mathrm{HF} /$ basis- $\mathrm{A}$ and $\mathrm{MP} 2 /$ basis- $\mathrm{A}$ levels. The optimizations have been carried out in $C_{2 h}$ symmetry for both systems, and the results are shown in Figure 5 . HF harmonic vibrational frequency analysis (cf. section VII) characterizes the $C_{2 h}$ structure as a minimum for $\left(\mathrm{HgF}_{2}\right)_{2}$.

Both dimers represent relatively loose dipole-dipole complexes of the monomers, with only small changes in the monomer structures. However, some differences between $\left(\mathrm{HgF}_{4}\right)_{2}$ and $\left(\mathrm{HgF}_{2}\right)_{2}$ may be noted: In $\left(\mathrm{HgF}_{2}\right)_{2}$ the two secondary bridging $\mathrm{Hg} \cdot \mathrm{F}$ contacts are shorter ( 2.506 vs $2.592 \AA$ at the MP2 level), and the lengthening of the primary $\mathrm{Hg}-\mathrm{F}$ bond involved in bridging (compared to the trans terminal bond) is larger ( $0.050 \mathrm{vs} 0.023$ $\AA)$. Consequently, the $\mathrm{Hg}-\mathrm{Hg}$ distance is slightly shorter $(3.663$ vs $3.688 \AA$ ). These structural data for the dimers of $\mathrm{HgF}_{4}$ and $\mathrm{HgF}_{2}$ suggest somewhat weaker aggregation for $\mathrm{HgF}_{4}$, as expected from the smaller $\mathrm{Hg}-\mathrm{F}$ charge separation (cf. Table 10).

The MP2(HF) dimerization energies for $\mathrm{HgF}_{2}$ and $\mathrm{HgF}_{4}$ are $71.6(79.9)$ and $66.3(52.9) \mathrm{kJ} \mathrm{mol}^{-1}$, respectively. Obviously, dimerization of $\mathrm{HgF}_{4}$ is somewhat less exothermic than that of $\mathrm{HgF}_{2}$, even though electron correlation favors dimerization of $\mathrm{HgF}_{4}$ but disfavors that of $\mathrm{HgF}_{2}$. More importantly, linear $\mathrm{HgF}_{2}$ has more possibilities of attaching other monomeric units than

(40) Ebert, F.; Woitinek, H. Z. Allg. Anorg. Chem. 1933, 210, 269. 
Table 19. ANO Valence Basis Sets for Mercury 20-Valence-Electron Pseudopotentials

\begin{tabular}{|c|c|c|c|c|}
\hline \multicolumn{5}{|c|}{ Quasirelativistic $\mathrm{Hg}$ Pseudopotential } \\
\hline s-expnt & $s-c o e f f 1$ & s-coeff 2 & s-coeff 3 & s-coeff 4 \\
\hline $\begin{array}{r}26.842049 \\
10.320909 \\
6.344923 \\
1.450305 \\
0.708215 \\
0.167606 \\
0.059066 \\
0.020000\end{array}$ & $\begin{array}{r}-0.016487 \\
0.481214 \\
-1.021718 \\
0.893341 \\
0.427171 \\
0.038220 \\
0.005940 \\
0.001638\end{array}$ & $\begin{array}{r}-0.005166 \\
0.192427 \\
-0.436569 \\
0.573754 \\
0.256109 \\
-0.729316 \\
-0.495895 \\
0.010126\end{array}$ & $\begin{array}{r}0.011839 \\
-0.482024 \\
1.149031 \\
-2.854086 \\
2.256339 \\
0.749619 \\
-1.274802 \\
0.155352\end{array}$ & $\begin{array}{r}0.064486 \\
0.006528 \\
-0.592358 \\
3.335126 \\
-4.245811 \\
3.256809 \\
-2.193251 \\
0.320303\end{array}$ \\
\hline p-expnt & \multicolumn{2}{|c|}{$\mathrm{p}$-coeff 1} & $\mathrm{p}$-coeff 2 & p-coeff 3 \\
\hline $\begin{array}{l}9.772990 \\
7.169095 \\
1.868009 \\
0.973301 \\
0.421997 \\
0.125213 \\
0.040190\end{array}$ & \multicolumn{2}{|c|}{$\begin{array}{r}0.215536 \\
-0.447460 \\
0.484007 \\
0.532591 \\
0.161311 \\
-0.000784 \\
0.001096\end{array}$} & $\begin{array}{l}15630 \\
50436 \\
67818 \\
42302 \\
79243 \\
18047 \\
10247\end{array}$ & $\begin{array}{r}-0.288793 \\
0.631343 \\
-1.662077 \\
0.851331 \\
1.012230 \\
-0.915838 \\
-0.065309\end{array}$ \\
\hline d-expnt & \multicolumn{2}{|c|}{ d-coeff 1} & d-coeff 2 & d-coeff 3 \\
\hline $\begin{array}{l}4.911447 \\
3.049550 \\
1.344501 \\
0.576618 \\
0.210245 \\
0.070000\end{array}$ & \multicolumn{2}{|c|}{$\begin{array}{r}-0.123758 \\
0.172640 \\
0.419545 \\
0.453967 \\
0.219740 \\
0.020652\end{array}$} & $\begin{array}{l}43204 \\
15568 \\
44942 \\
17081 \\
03492 \\
60935\end{array}$ & $\begin{array}{r}0.654694 \\
-1.556042 \\
0.293278 \\
1.025705 \\
-0.873026 \\
-0.118530\end{array}$ \\
\hline \multicolumn{5}{|c|}{ Nonrelativistic $\mathrm{Hg}$ Pseudopotential } \\
\hline s-expnt & s-coeff 1 & $s-\operatorname{coeff} 2$ & s-coeff 3 & $s-\operatorname{coeff} 4$ \\
\hline $\begin{array}{c}20.411181 \\
8.002190 \\
6.061546 \\
1.148707 \\
0.537926 \\
0.120312 \\
0.043510 \\
0.01500\end{array}$ & $\begin{array}{r}-0.044460 \\
1.303516 \\
-1.838583 \\
0.990380 \\
0.346961 \\
0.021675 \\
0.001368 \\
0.001296\end{array}$ & $\begin{array}{r}0.014357 \\
-0.453773 \\
0.656566 \\
-0.504472 \\
-0.238695 \\
0.741711 \\
0.470478 \\
-0.012288\end{array}$ & $\begin{array}{r}0.027386 \\
-1.208637 \\
1.838931 \\
-2.812316 \\
2.360890 \\
0.551800 \\
-1.154127 \\
0.155561\end{array}$ & $\begin{array}{r}0.059987 \\
0.275483 \\
-0.788059 \\
2.831256 \\
-3.712767 \\
3.270419 \\
-2.435382 \\
0.423676\end{array}$ \\
\hline p-expnt & \multicolumn{2}{|c|}{$\mathrm{p}$-coeff 1} & p-coeff 2 & $p$-coeff 3 \\
\hline $\begin{array}{l}9.283858 \\
6.521945 \\
1.686345 \\
0.879019 \\
0.393181 \\
0.112522 \\
0.037595\end{array}$ & \multicolumn{2}{|c|}{$\begin{array}{r}0.189483 \\
-0.427772 \\
0.508884 \\
0.511817 \\
0.157464 \\
0.000328 \\
0.000750\end{array}$} & $\begin{array}{l}81218 \\
90531 \\
92713 \\
41404 \\
41368 \\
10877 \\
73943\end{array}$ & $\begin{array}{r}0.245753 \\
-0.579889 \\
1.527622 \\
-0.558702 \\
-1.148583 \\
0.690869 \\
0.195725\end{array}$ \\
\hline d-expnt & \multicolumn{2}{|c|}{$d$-coeff 1} & d-coeff 2 & d-coeff 3 \\
\hline $\begin{array}{l}5.019562 \\
2.713801 \\
1.257831 \\
0.55344 \\
0.212165 \\
0.070000\end{array}$ & $\begin{array}{r}-0.102 \\
0.188 \\
0.437 \\
0.427 \\
0.186 \\
0.014\end{array}$ & $\begin{array}{r}0 . \\
-0 . \\
-0 . \\
0 . \\
0 . \\
0 .\end{array}$ & $\begin{array}{l}04995 \\
59717 \\
93434 \\
37204 \\
39035 \\
48959\end{array}$ & $\begin{array}{r}0.462876 \\
-1.485871 \\
0.567210 \\
0.895729 \\
-0.901531 \\
-0.130511\end{array}$ \\
\hline
\end{tabular}

- For pseudopotentials from ref 11 .

the planar molecule $\mathrm{HgF}_{4}$. Indeed, in the solid state $\mathrm{HgF}_{2}$ adopts the ionic fluorite structure with $8 \cdot$ coordination of mercury. ${ }^{40} \mathrm{In}$ contrast, the most probable arrangement for $\mathrm{HgF}_{4}$ is stacking of the square planar $d^{8}$ monomers with only two secondary contacts for each mercury atom (leading to a $4+2$ coordination). A structure of this type has been found for $\mathrm{XeF}_{4}{ }^{41}$ The resulting aggregation energy doubtlessly is much lower than that for $\mathrm{HgF}_{2}$ (which has a sublimation enthalpy of ca. $120-130 \mathrm{~kJ} \mathrm{~mol}^{-1}$ ).42

(41) Templeton, D. H.; Zalkin, A.; Forrester, J. D.; Williamson, S. M. J. Am. Chem. Soc. 1963, 85, 242.

(42) Estimated from heats of formation for solid and gaseous $\mathrm{HgF}_{2}$ given in JANAF Thermochemical Tables, 2nd ed.; Stull, D. R., Prophet, $H$. Eds.; Natural Bureau of Standards: Washington, DC, 1971.
Table 20. ANO Valence Basis Set for Quasirelativistic Cadmium 20-Valence-Electron Pseudopotentiale

\begin{tabular}{crrrr}
\hline s-expnt & s-coeff 1 & s-coeff 2 & s-coeff 3 & s-coeff 4 \\
\hline 9.727011 & 0.967898 & -0.347970 & -1.176847 & 3.218841 \\
7.837523 & -1.401764 & 0.520824 & 1.835648 & -5.889629 \\
5.089194 & -0.073772 & 0.009981 & -0.095058 & 2.739625 \\
1.553326 & 0.852104 & -0.407956 & -2.430015 & 1.919264 \\
0.714079 & 0.443150 & -0.285253 & 1.868638 & -3.077957 \\
0.150784 & 0.030623 & 0.618139 & 0.912628 & 2.835407 \\
0.057467 & 0.004705 & 0.548977 & -1.266437 & -1.924260 \\
0.019000 & 0.002343 & 0.021916 & 0.092126 & 0.126569 \\
\hline p-expnt & p-coeff 1 & p-coeff 2 & -coeff 3 \\
\hline 4.742716 & -1.049832 & 0.617143 & -2.011322 \\
3.936655 & 1.110445 & -0.703302 & 2.450079 \\
1.380391 & 0.624199 & -0.300787 & 0.727893 \\
0.668485 & 0.233283 & -0.185063 & -1.344653 \\
0.363423 & 0.055227 & 0.569862 & -0.212347 \\
0.106253 & 0.001740 & 0.680502 & 0.694924 \\
0.036644 & -0.000175 & 0.017220 & 0.087590 \\
\hline d-expnt & d-coeff 1 & d-coeff 2 & d-coeff 3 \\
\hline 8.469341 & -0.015327 & 0.050344 & -0.079520 \\
3.024231 & 0.267775 & -0.600169 & 1.154211 \\
1.316367 & 0.444068 & -0.364616 & -0.978167 \\
0.556393 & 0.352313 & 0.593813 & -0.425793 \\
0.223856 & 0.150063 & 0.408705 & 0.821822 \\
0.075000 & 0.015065 & 0.053367 & 0.122709 \\
0 & & &
\end{tabular}

a For Cd pseudopotential from ref 11

Table 21. ANO Valence Basis Set for Quasirelativistic Zinc 20-Valence-Electron Pseudopotential ${ }^{a}$

\begin{tabular}{rrrrr}
\hline s-expnt & \multicolumn{1}{c}{ s-coeff 1} & \multicolumn{1}{c}{ s-coeff 2} & \multicolumn{1}{c}{ s-coeff 3} & s-coeff 4 \\
\hline 30.324127 & 0.090591 & -0.023257 & -0.171684 & 0.326101 \\
16.316682 & -0.133220 & 0.037145 & 0.588268 & -1.485539 \\
11.408148 & -0.319948 & 0.083349 & -0.092616 & 1.109691 \\
2.569492 & 0.730710 & -0.248065 & -1.894619 & 1.511895 \\
1.062595 & 0.478508 & -0.242124 & 1.583970 & -2.089971 \\
0.151553 & 0.022035 & 0.680726 & 0.705257 & 2.129321 \\
0.052747 & -0.003885 & 0.452855 & -1.044017 & -1.689036 \\
0.010000 & 0.001489 & 0.003569 & 0.080568 & 0.123022 \\
\hline
\end{tabular}

\begin{tabular}{rrrr}
\hline \multicolumn{1}{c}{ p-expnt } & p-coeff 1 & p-coeff 2 & \multicolumn{1}{c}{ p-coeff 3 } \\
\hline 111.824980 & 0.002125 & -0.000636 & -0.003261 \\
19.131910 & -0.085188 & 0.032069 & 0.141597 \\
5.468838 & 0.243882 & -0.118164 & -0.818579 \\
2.505675 & 0.569141 & -0.258713 & -0.262107 \\
0.941868 & 0.317048 & 0.121553 & 1.168271 \\
0.171131 & 0.013626 & 0.864863 & -0.379971 \\
0.049986 & -0.002924 & 0.134839 & -0.206282 \\
& & & \\
\hline d-expnt & d-coeff 1 & d-coeff 2 & d-coeff 3 \\
\hline 44.645629 & 0.041019 & 0.050970 & -0.048688 \\
13.438377 & 0.187650 & 0.254468 & -0.425250 \\
4.682000 & 0.388106 & 0.540314 & -0.295173 \\
1.603211 & 0.439618 & -0.189883 & 1.050903 \\
0.482766 & 0.283175 & -0.654385 & -0.583764 \\
0.110000 & 0.048730 & -0.149999 & -0.374885
\end{tabular}

${ }^{a}$ For $\mathrm{Zn}$ pseudopotential from ref 10 .

\section{Conclusions}

Quasirelativistic ab initio pseudopotential calculations, using extended ANO basis sets and high-level methods (QCISD, QCISD $(T))$ for the treatment of electron correlation, show that mercury tetrafluoride, $\mathrm{HgF}_{4}$, should exist as a free molecule in the gas phase. The gas-phase reaction $\mathrm{HgF}_{4} \rightarrow \mathrm{HgF}_{2}+\mathrm{F}_{2}$ probably is slightly endothermic. In contrast, the existence of $\mathrm{CdF}_{4}$ and particularly of $\mathrm{ZnF}_{4}$ is unlikely, as the elimination of $F_{2}$ from these metal(IV) fluorides is significantly exothermic. These differences between the lighter group 12 and mercury fluorides are mainly due to the large relativistic destabilization of $\mathrm{HgF}_{2}$ and not to a direct relativistic stabilization of $\mathrm{HgF}_{4}$ itself. 
Table 22. ANO Valence Basis Set for Quasirelativistic Fluorine 7-Valence-Electron Pseudopotential ${ }^{a}$

\begin{tabular}{crrr}
\hline s-expnt & \multicolumn{1}{c}{ s-coeff 1} & \multicolumn{1}{c}{ s-coeff 2} & \multicolumn{1}{c}{ s-coeff 3} \\
\hline 57.845327 & 0.007392 & 0.006015 & 0.001029 \\
8.994522 & -0.161407 & -0.225836 & -0.048462 \\
1.578064 & 0.318474 & 1.495848 & 0.385169 \\
0.827850 & 0.336630 & -0.272939 & -0.177342 \\
0.413156 & 0.388629 & -0.572064 & -0.136198 \\
0.162845 & 0.094838 & -0.610856 & -0.036944 \\
0.090 & -0.005882 & 0.106083 & 0.025648 \\
\hline p-expnt & p-coeff 1 & p-coeff 2 & \multicolumn{1}{c}{ p-coeff 2} \\
\hline 51.771383 & 0.012288 & 0.018142 & -0.027959 \\
13.992922 & 0.070477 & 0.094751 & -0.158059 \\
4.291980 & 0.221969 & 0.406090 & -0.857131 \\
1.458226 & 0.408269 & 0.496918 & 0.807635 \\
0.473095 & 0.422363 & -0.613845 & 0.444991 \\
0.129965 & 0.200644 & -0.603147 & -1.310470 \\
0.090 & -0.053556 & 0.184486 & 0.503669
\end{tabular}

a For $\mathrm{F}$ pseudopotential from ref 13 . To this basis, three d-functions with $\alpha=3.6,0.9$, and 0.225 and one $f$-function with $\alpha=1.85$ were added.

Possible preparation routes for $\mathrm{HgF}_{4}$, based on oxidation of $\mathrm{HgF}_{2}$ by $\mathrm{KrF}_{2}$, on photochemical oxidation, or on direct thermal fluorination, have been discussed. Computational comparison of the model anions $\mathrm{HgF}_{5}-\mathrm{HgF}_{6}{ }^{-2}, \mathrm{HgF}_{3}{ }^{-}$, and $\mathrm{HgF}_{4}{ }^{2-}$ indicates that there is no significant stabilization of $\mathrm{Hg}$ (IV) vs. $\mathrm{Hg}$ (II) by anionic complexation. Similarly, comparison of the dimerization of $\mathrm{HgF}_{4}$ to that of $\mathrm{HgF}_{2}$ suggests a larger stabilization of $\mathrm{HgF}_{2}$ by aggregation. Thus, $\mathrm{HgF}_{4}$ probably is more volatile than $\mathrm{HgF}_{2}$, and any preparation route will have to take into account that lattice energy will favor $\mathrm{HgF}_{2}+\mathrm{F}_{2}$ over $\mathrm{HgF}_{4}$.

Harmonic vibrational frequencies for $\mathrm{HgF}_{4}, \mathrm{HgF}_{2}$, and $\left(\mathrm{HgF}_{2}\right)_{2}$ have been calculated to aid the experimental identification of $\mathrm{HgF}_{4}$. The electronic structures of the group $12 \mathrm{di}-$ and tetrafluorides have been studied by natural population analysis and hybridization analysis. Obviously, the tetrafluorides involve
Table 23. Atomic ACPF Contraction Errors (au) for ANO Valence Basis Sets

\begin{tabular}{ccccc}
\hline $\mathrm{Hg}(\mathrm{rel})^{a}$ & $\mathrm{Hg}(\mathrm{nr})^{b}$ & $\mathrm{Cd}$ & $\mathrm{Zn}$ & $\mathrm{F}$ \\
\hline 0.015 & 0.017 & 0.025 & 0.046 & 0.004
\end{tabular}

${ }^{a}$ With quasirelativistic pseudopotential. ${ }^{b}$ With nonrelativistic pseudopotential.

the $(n-1) d$-orbitals in bonding to a significant extent. Thus, they are genuine low-spin $d^{8}$ transition metal compounds, whereas the difluorides are true ionic main group (post-transition metal $\left.\mathrm{d}^{10}\right)$ species.

The performance of the MP2 method and the importance of triple substitutions in quadratic $\mathrm{CI}$ calculations for the relative energies and structures of the group $12 \mathrm{di}$ - and tetrafluorides have been discussed. Interestingly, for $\mathrm{HgF}_{4}$ but not for $\mathrm{HgF}_{2}$ there is a considerable interdependence of relativistic effects (on bond lengths and binding energies) and the level of treatment of electron correlation. This is due to significant nondynamical correlation contributions in $\mathrm{HgF}_{4}$. These are somewhat smaller in the relativistic than in the nonrelativistic pseudopotential calculations.

Note Added in Proof. The addition of a metal g-function ( $\delta$ $=1.7$ ) in the ANO-QCISD(T) calculations changes the atomization energies of $\mathrm{HgF}_{4}$ and $\mathrm{HgF}_{2}$ by less than $3 \mathrm{~kJ} \mathrm{~mol}^{-1}$ and the reaction energy for $\mathrm{HgF}_{4} \rightarrow \mathrm{HgF}_{2}+\mathrm{F}_{2}$ by less than $1 \mathrm{~kJ}$ $\mathrm{mol}^{-1}$.

Acknowledgment. We thank Prof. B. Müller (Universität Giessen) for informing us about unpublished attempts to synthesize $\mathrm{HgF}_{4}$.

\section{Appendix}

Tables 19-22 give the atomic-natural-orbital (ANO) valence basis-sets for $\mathrm{Hg}, \mathrm{Cd}, \mathrm{Zn}$, and $\mathrm{F}$, respectively. The $\mathrm{ACPF}$ contraction errors are summarized in Table 23. 